This item was submitted to Loughborough's Research Repository by the author.

Items in Figshare are protected by copyright, with all rights reserved, unless otherwise indicated.

\title{
Global drivers, sustainable manufacturing and systems ergonomics
}

PLEASE CITE THE PUBLISHED VERSION

http://dx.doi.org/10.1016/j.apergo.2015.04.018

\section{PUBLISHER}

(c) Elsevier Ltd and The Ergonomics Society

\section{VERSION}

AM (Accepted Manuscript)

\section{PUBLISHER STATEMENT}

This work is made available according to the conditions of the Creative Commons Attribution-NonCommercialNoDerivatives 4.0 International (CC BY-NC-ND 4.0) licence. Full details of this licence are available at: https://creativecommons.org/licenses/by-nc-nd/4.0/

\section{LICENCE}

CC BY-NC-ND 4.0

\section{REPOSITORY RECORD}

Siemieniuch, Carys E., Murray A. Sinclair, and Michael Henshaw. 2019. "Global Drivers, Sustainable Manufacturing and Systems Ergonomics”. figshare. https://hdl.handle.net/2134/18289. 


\title{
Global Drivers, sustainable manufacturing and Systems Ergonomics
}

\author{
C.E. Siemieniuch, M.A. Sinclair, M.J.deC. Henshaw \\ Engineering Systems of Systems Research Group \\ Systems Division, School of Electronic, Electrical \& Systems Engineering \\ Loughborough University LE11 3TU
}

Contact M.A. Sinclair

T: 07703050041

E: murray.sinclair@icloud.com 


\title{
Global Drivers, sustainable manufacturing and Systems Ergonomics
}

\begin{abstract}
This paper briefly explores the expected impact of the 'Global Drivers' (such as population demographics, food security; energy security; community security and safety), and the role of sustainability engineering in mitigating the potential effects of these Global Drivers. The message of the paper is that sustainability requires a significant input from Ergonomics/ Human Factors, but the profession needs some expansion in its thinking in order to make this contribution.
\end{abstract}

Creating a future sustainable world in which people experience an acceptable way of life will not happen without a large input from manufacturing industry into all the Global Drivers, both in delivering products that meet sustainability criteria (such as durability, reliability, minimised material requirement and low energy consumption), and in developing sustainable processes to deliver products for sustainability (such as minimum waste, minimum emissions and low energy consumption). Appropriate changes are already being implemented in manufacturing industry, including new business models, new jobs and new skills.

Considerable high-level planning around the world is in progress and is bringing about these changes; for example, there is the US 'Advanced Manufacturing National Program' (AMNP)', the German 'Industrie 4.0' plan, the French plan 'la nouvelle France industrielle' and the UK Foresight publications on the 'Future of Manufacturing'.

All of these activities recognise the central part that humans will continue to play in the new manufacturing paradigms; however, they do not discuss many of the issues that systems ergonomics professionals acknowledge. This paper discusses a number of these issues, highlighting the need for some new thinking and knowledge capture by systems ergonomics professionals. Among these are ethical issues, job content and skills issues.

Towards the end, there is a summary of knowledge extensions considered necessary in order that Systems Ergonomists can be fully effective in this new environment, together with suggestions for the means to acquire and disseminate the knowledge extensions.

Keywords: Sustainability; Manufacturing; Systems Ergonomics; Cyber-Physical Systems engineering

\section{Introduction}


This paper is focused on the domain of manufacturing, and discusses this topic mainly from the perspective of the European Union (EU27), considered as a trading bloc of some 500 million people.

This focus on manufacturing is justified by the argument that on whatever aspect of sustainability one chooses to focus (e.g. food security, energy, water resources, emissions, health care), sustainability implies continuously-necessary, long-term processes. It is also certain that these processes will entrain manufactured products that are both sustainable in themselves, and are manufactured by sustainable processes. Manufacturing can therefore be considered to be fundamental to sustainability. Because of the extensive role of human beings in manufacturing (strategy, knowledge, design, control, resilience, etc.), the Ergonomics/ Human Factors profession has a fundamental role in sustainability.

The purpose of the paper is to outline some of the changes that will happen in the manufacturing domain up to 2050, or thereabouts, since this corresponds to the forward view adopted in many other countries as well as the EU27, and to explore what these mean for Systems Ergonomics professionals. Since all of the countries that have published their thinking about the future of manufacturing have acknowledged the centrality of people, it seems appropriate to prepare the ground for the application of appropriate ergonomics/human factors understanding to the changed roles and likely different relationships that will exist in these future scenarios

The paper is divided into three parts. Part one discusses some of the implications of Global Drivers, indicating their potential effects on society. These effects may be ameliorated by adopting a 'sustainable' economy, minimising the effects of the drivers themselves, and ensuring that there are resources available for future generations in the societies of their time. Part two outlines how manufacturing is likely to adapt to help deliver this sustainable world. We concentrate on manufacturing on the grounds that it is the artefacts of manufacturing that will be used in other domains to achieve sustainability in those domains - the built environment, transport, agriculture, space, etc.

Since current thinking has humans at the heart of future developments, Part three discusses a number of system ergonomics issues pertinent to the new manufacturing environments; issues that go beyond current practice, particularly in the realm of systems of systems (SoS), and increasingly the subarea of cyber-physical systems (CPS).

\section{PART ONE: 'Global Drivers' and their likely combined impacts on society}

To provide some purchase on the notion of global drivers, we present a list of these drivers, and a table to indicate their potential effects on our societies and the world. Following a suggestion by one of the paper's referees, we point out that the comments in this section are based on forecasts and strategy documents of governments and other national and international organisations. 


\subsection{An outline of the global drivers}

Global drivers as identified in the Sulston report and the Working Group $5^{\text {th }}$ Assessment Reports of the IPCC are considered mostly from a longer-term perspective; the trends are extrapolated to about 2050 in most of the documents.

Based on this perspective, and focusing on the EU27 as a significant global entity, the following inter-related global drivers can be identified:

- Population demographics, including lifestyles, growth and aging

- Food security

- Energy security

- Resource depletion

- Emissions and global climate

- Community security and safety

- Transportation

- Globalisation of economic and social activity

A brief outline of the effects of the global drivers on the EU27 follows, in Table 1. 


\begin{tabular}{|c|c|c|c|c|}
\hline Driver & Characteristics & Likely effects & Sustainability issues & Sources \\
\hline $\begin{array}{l}\text { Population } \\
\text { demographics }\end{array}$ & 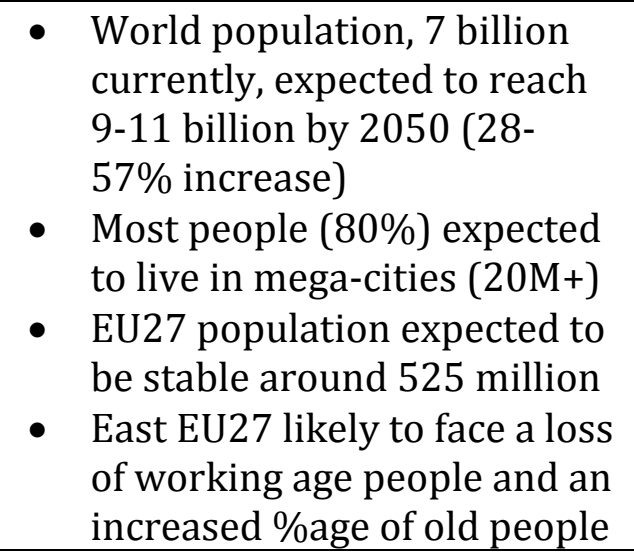 & 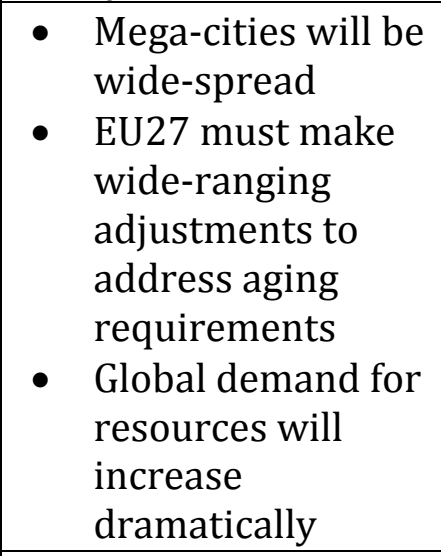 & 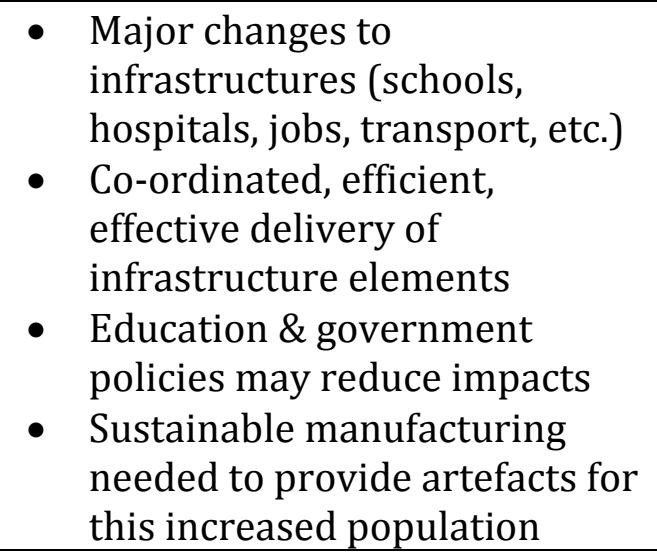 & $\begin{array}{l}\text { (UN-DESA 2004, } \\
\text { Allwood, Ashby et } \\
\text { al. 2011, Eurostat } \\
\text { 2011, Lee, Preston } \\
\text { et al. 2012, Rees, } \\
\text { Gaag et al. 2012, } \\
\text { Sulston 2012, IPCC- } \\
\text { WGII 2014) }\end{array}$ \\
\hline Food security & $\begin{array}{l}\text { Crop-land growth not } \\
\text { keeping pace with population } \\
\text { growth; fisheries are } \\
\text { depleted } \\
\text { - Food wastage from seeds to } \\
\text { garbage significant in all } \\
\text { states, (rich waste food, poor } \\
\text { suffer from poor husbandry) }\end{array}$ & $\begin{array}{l}\text { Climate change } \\
\text { will affect supply } \\
\text { (drought, storms, } \\
\text { heat) } \\
\text { - Local food } \\
\text { shortages likely } \\
\text { Disruptions to } \\
\text { global food chains }\end{array}$ & $\begin{array}{l}\text { More efficient supply chains } \\
\text { will be needed. } \\
\text { - Food wastage, diet preferences } \\
\text { need culture change. } \\
\text { - Crop engineering needed to } \\
\text { reduce inputs, water } \\
\text { - Machinery improvements are } \\
\text { needed, everywhere }\end{array}$ & $\begin{array}{l}\text { (McMichael and } \\
\text { Dear 2010, Allouche } \\
\text { 2011, Lee, Preston } \\
\text { et al. 2012, } \\
\text { Levermann 2014) }\end{array}$ \\
\hline $\begin{array}{l}\text { Energy } \\
\text { security }\end{array}$ & $\begin{array}{l}\text { EU27 imports about } 60 \% \text { of } \\
\text { its gas, about } 80 \% \text { of its oil, } \\
\text { both non-renewable } \\
\text { - Provision of energy } \\
\text { becoming more volatile, less } \\
\text { reliable } \\
\text { Population growth, coupled } \\
\text { with ever-increasing energy } \\
\text { demand per person indicate } \\
\text { unsustainable future demand }\end{array}$ & 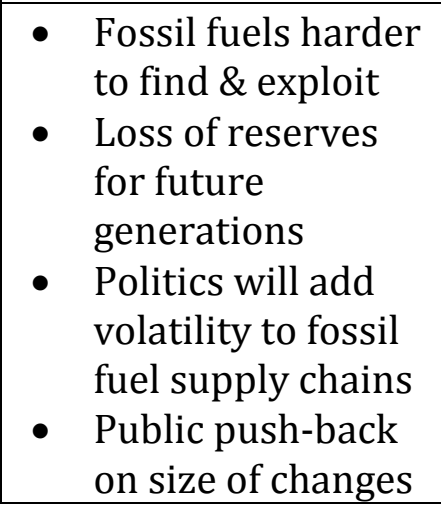 & $\begin{array}{l}\text { - Leave fossil fuels in the ground } \\
\text { Big drops in energy use by } \\
\text { manufacturing, construction, } \\
\text { transport \& end-users } \\
\text { - Regulation to encourage a } \\
\text { sustainability approach; } \\
\text { ECODESIGN in the EU \& Top- } \\
\text { runner' in Japan are examples } \\
\text { for energy reduction }\end{array}$ & $\begin{array}{l}\text { (Tojo and Tanaka } \\
\text { 2005, MoE(Japan) } \\
\text { 2008, ECecodesign } \\
\text { 2009, Allwood, } \\
\text { Ashby et al. 2011, } \\
\text { EC-Energy 2011, } \\
\text { IEA 2011, World- } \\
\text { Bank 2012, } \\
\text { Gutowski, Sahni et } \\
\text { al. 2013) }\end{array}$ \\
\hline
\end{tabular}




\begin{tabular}{|c|c|c|c|c|}
\hline $\begin{array}{l}\text { Mineral } \\
\text { resource } \\
\text { depletion }\end{array}$ & $\begin{array}{l}\text { - Some important minerals are } \\
\text { in short supply (e.g. 'rare } \\
\text { earths', lithium, titanium) } \\
\text { - As depletion occurs, ores } \\
\text { become lower in quality and } \\
\text { are less accessible. }\end{array}$ & $\begin{array}{l}\text { - Costs likely to } \\
\text { increase. } \\
\text { - 'linear' (i.e. from } \\
\text { ore to waste tip) } \\
\text { usage of materials } \\
\text { may become } \\
\text { unviable; 'circular' } \\
\text { (e.g. recycling) } \\
\text { processes may } \\
\text { become essential }\end{array}$ & $\begin{array}{l}\text { More costly minerals and fuels } \\
\text { will force manufacturers into } \\
\text { energy efficiency \& recycling. } \\
\text { Legislation will be needed to } \\
\text { create incentives (industry } \\
\text { 'pull') and regulations ('push') } \\
\text { to be sustainable } \\
\text { - Create change to business } \\
\text { models and customer culture } \\
\text { - Standards and certification } \\
\text { will be necessary. }\end{array}$ & $\begin{array}{l}\text { (Allwood, Ashby et } \\
\text { al. 2011, Lee, } \\
\text { Preston et al. 2012, } \\
\text { Prior, Giurco et al. } \\
\text { 2012, Gutowski, } \\
\text { Sahni et al. 2013, } \\
\text { Kagermann, } \\
\text { Wahlster et al. } \\
\text { 2013, Lavery, Penell } \\
\text { et al. 2013, } \\
\text { Lavery/Penell } \\
\text { 2014) }\end{array}$ \\
\hline $\begin{array}{l}\text { Emissions \& } \\
\text { global climate }\end{array}$ & $\begin{array}{l}\text { Sequence of IPCC reports } \\
\text { show that emissions are } \\
\text { driving climate change. } \\
\text { About } 50 \% \text { of world's } \\
\text { population rely on coal or } \\
\text { biomass for domestic energy; } \\
\text { 20\% have no access to } \\
\text { electricity. } \\
\text { More demand for heating/ } \\
\text { cooling in buildings. }\end{array}$ & $\begin{array}{l}\text { - IPCC reports show } \\
\text { a 'tipping point' } \\
\text { for climate change } \\
\text { may be reached. } \\
\text { - Severe weather } \\
\text { events more likely } \\
\text { - More heat in } \\
\text { hot/humid areas } \\
\text { may cut human } \\
\text { work capacity \& } \\
\text { agriculture }\end{array}$ & $\begin{array}{l}\text { Widespread changes needed } \\
\text { to reduce emissions - } \\
\text { sustainable energy sources, } \\
\text { better grids, less usage } \\
\text { - Electricity supply extended } \\
\text { into poorer countries, with } \\
\text { benefits - health, work, etc. } \\
\text { - Reduced energy usage } \\
\text { requires better devices, } \\
\text { standards, networks hence } \\
\text { international action needed }\end{array}$ & $\begin{array}{l}\text { (WETO-H2 2006, } \\
\text { Siderius and } \\
\text { Nakagami 2007, } \\
\text { 2009/125/EC } \\
\text { 2009, IEA 2010, } \\
\text { Zivin and Niedell } \\
\text { 2010, EC2011 } \\
\text { 2011, EC-Energy } \\
\text { 2011, World-Bank } \\
\text { 2012, Gutowski, } \\
\text { Sahni et al. 2013) }\end{array}$ \\
\hline Transportation & $\begin{array}{l}\text { Transportation is essential to } \\
\text { the global economy, hence to } \\
\text { the perceived well-being of } \\
\text { its citizens. } \\
\text { - Population growth \& } \\
\text { prosperity will increase } \\
\text { demand for transportation }\end{array}$ & $\begin{array}{l}\text { Transportation is } \\
\text { a significant user } \\
\text { of energy; } \\
\text { - Energy sources } \\
\text { mainly carbon- } \\
\text { based } \\
\text { - Poorer countries } \\
\text { need much better } \\
\text { transport }\end{array}$ & $\begin{array}{l}\text { - } \\
\text { Need to improve the energy } \\
\text { - } \quad \text { Non-carbon energy sources } \\
\text { - Intelligent networks for } \\
\text { transportation efficiency. } \\
\text { - Extend shrinkage, } \\
\text { minimisation, miniaturisation } \\
\text { \& dematerialisation of goods }\end{array}$ & $\begin{array}{l}\text { (Guitink, Holste et } \\
\text { al. 1994, O'Neill } \\
\text { 2009, Allwood, } \\
\text { Ashby et al. 2011, } \\
\text { EC-Transport 2011, } \\
\text { Allwood, Ashby et } \\
\text { al. 2012, Lee, } \\
\text { Preston et al. 2012, } \\
\text { Gutowski, Sahni et } \\
\text { al. 2013) }\end{array}$ \\
\hline
\end{tabular}




\begin{tabular}{|c|c|c|c|c|}
\hline $\begin{array}{l}\text { Globalisation } \\
\text { of economic \& } \\
\text { social activity }\end{array}$ & $\begin{array}{l}\text { Benefits to developed } \\
\text { countries include access to } \\
\text { non-local produce and goods; } \\
\text { to developing countries, their } \\
\text { economies can diversify from } \\
\text { produce and raw materials. } \\
\text { Increasing pervasion and } \\
\text { interconnection of IT systems } \\
\text { opens opportunities for } \\
\text { improvements, but also } \\
\text { amplifies the negative effects } \\
\text { of the other global drivers }\end{array}$ & $\begin{array}{l}\text { - Global benefits } \\
\text { tend to come with } \\
\text { local disruptions } \\
\text { - Equitable benefits } \\
\text { for populations } \\
\text { will require both } \\
\text { regulation and } \\
\text { incentives, as well } \\
\text { as attention to } \\
\text { standards safety } \\
\text { and security } \\
\text { - Government and } \\
\text { inter-government } \\
\text { actions will be } \\
\text { required }\end{array}$ & $\begin{array}{l}\text { A sustainable world will } \\
\text { disrupt current certainties, } \\
\text { cultural values, and accepted } \\
\text { orthodoxies. There will be } \\
\text { resistance to the changes,. } \\
\text { - Sustainability projects will } \\
\text { require widespread } \\
\text { preparation to address } \\
\text { concerns, \& cultural issues. } \\
\text { Big sustainability projects will } \\
\text { need global consideration: } \\
\text { materials, treaties and } \\
\text { economics of global trade. } \\
\text { Government involvement } \\
\text { needed for good governance. }\end{array}$ & $\begin{array}{l}\text { (UN-DESA 2004, } \\
\text { EC-ET 2006, } \\
\text { Naumann 2006, } \\
\text { Dahmann and } \\
\text { Baldwin 2008, UN- } \\
\text { FAO 2009, deWeck, } \\
\text { Roos et al. 2011, } \\
\text { Aguirre, Hoteit et al. } \\
\text { 2012, Batty, } \\
\text { Axhausen et al. } \\
\text { 2012, Lee, Preston } \\
\text { et al. 2012, Sulston } \\
\text { 2012, World-Bank } \\
\text { 2012, UNEP 2013, } \\
\text { WEF 2013) }\end{array}$ \\
\hline $\begin{array}{l}\text { Community } \\
\text { safety \& } \\
\text { security }\end{array}$ & $\begin{array}{l}\text { - Increasing pervasion and } \\
\text { interconnection of IT systems } \\
\text { opens opportunities both for } \\
\text { economic and social } \\
\text { improvements, and for } \\
\text { malicious activities aimed at } \\
\text { people, infrastructures and } \\
\text { businesses } \\
\text { - Mega-cities may result from } \\
\text { unmanaged growth, leading } \\
\text { to unwanted social } \\
\text { inequities. }\end{array}$ & $\begin{array}{l}\text { More asymmetric } \\
\text { attacks (small } \\
\text { cost, big effect) on } \\
\text { critical networks } \\
\text { - } \text { Increase in } \\
\text { 'normal accidents' } \\
\text { due to increasing } \\
\text { complexities } \\
\text { - Possibility of of } \\
\text { more social } \\
\text { inequality \& } \\
\text { increases in } \\
\text { 'digital divide' }\end{array}$ & $\begin{array}{l}\text { Ashby's Law: more societal } \\
\text { complexity means more } \\
\text { complexity of governance } \\
\text { New approaches, methods, } \\
\text { thinking needed for greater } \\
\text { complexity in society } \\
\text { - Continuous attention to } \\
\text { vulnerabilities in critical } \\
\text { infrastructures needed } \\
\text { - Human ingenuity and } \\
\text { competence still primary in } \\
\text { this technological world } \\
\text { - Ethical \& cultural issues will } \\
\text { become significant factors } \\
\text { Standards and certification } \\
\text { will be critical to operations. }\end{array}$ & $\begin{array}{l}\text { (Turner and } \\
\text { Pidgeon 1997, } \\
\text { Perrow 1999, Daw } \\
\text { 2007, Siemieniuch } \\
\text { and Sinclair 2008, } \\
\text { Pétrissans, } \\
\text { Krawczyk et al. } \\
\text { 2012, Vlacheas, } \\
\text { Giaffreda et al. } \\
\text { 2013, Ortiz, Hussein } \\
\text { et al. 2014, } \\
\text { Siemieniuch and } \\
\text { Sinclair 2014) }\end{array}$ \\
\hline
\end{tabular}

Table 1 An outline of the Global Drivers, their likely effects and characteristics, together with mitigation possibilities, and further reading 
Figures $1 \mathrm{a}$ and $1 \mathrm{~b}$ below indicate some of the high-level interactions between the global drivers, and classes of actions required for mitigation Both diagrams treat population growth as a main driver, following Sulston 2012.

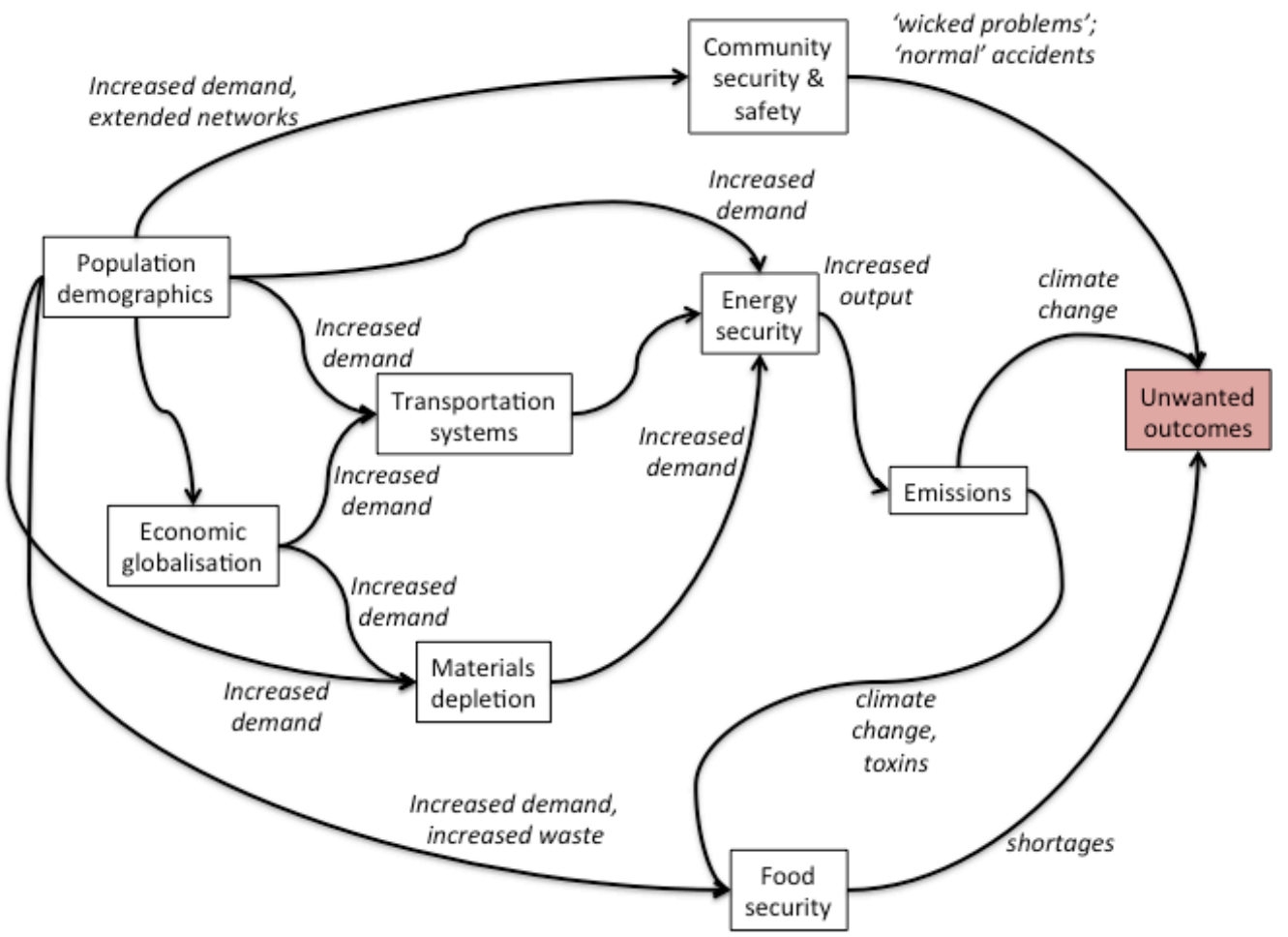

Figure 1a Illustration of the high-level interactions between the Global Drivers, leading to unwanted outcomes. Only one set of interactions are shown, arising from a growth in population. Similar interactions could be drawn from the other global drivers..

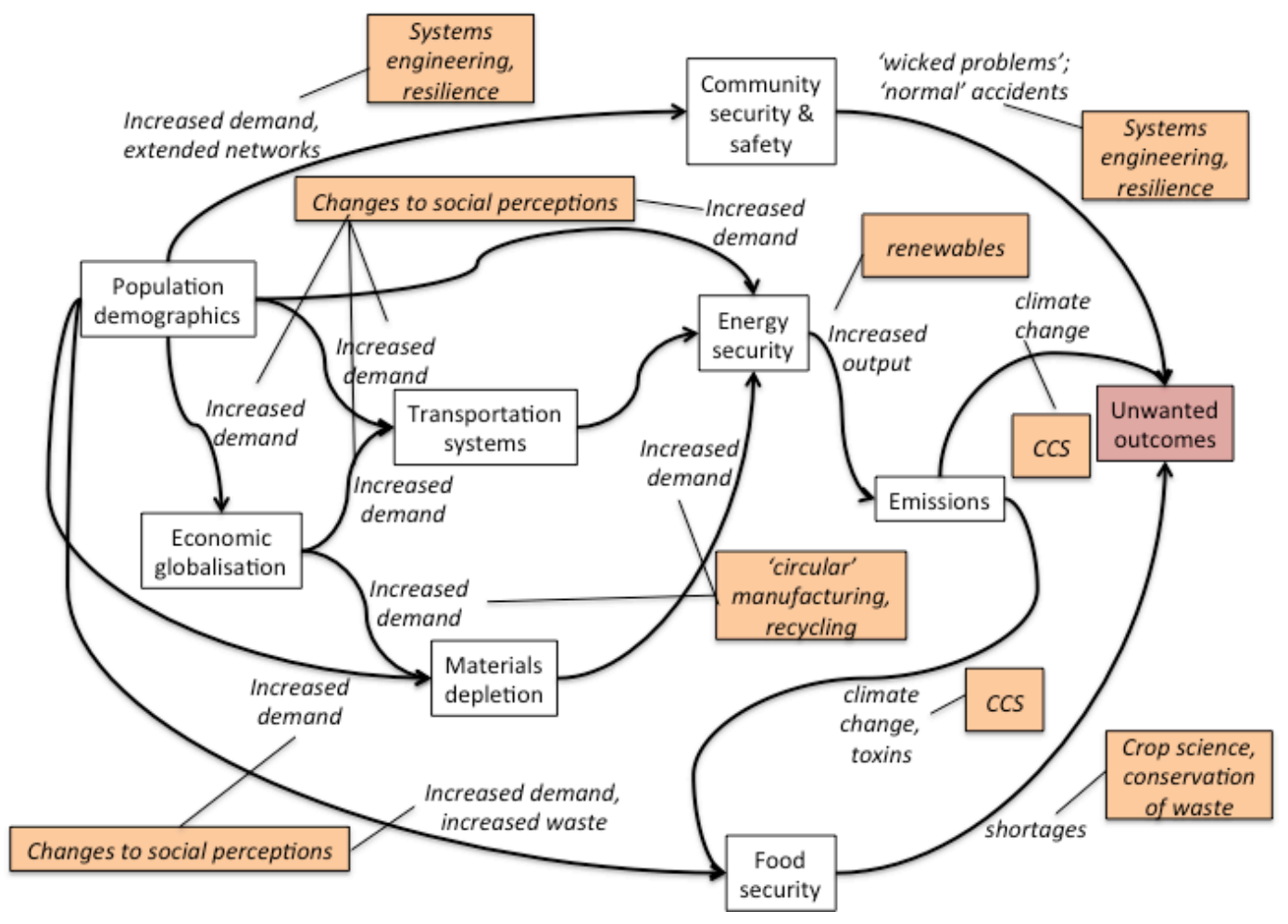


Figure $1 \mathrm{~b}$ Indicating actions that could lead to mitigation of the negative outcomes in Fig. 1a.

Taking Figures $1 \mathrm{a}$ and $1 \mathrm{~b}$ together with Table 1, three conclusions may be drawn about these Global Drivers;

- Each of the Global Drivers, operating on its own, could have very significant effects on the world as a whole, and on the EU27. Together, they pose a significant threat to the health and well-being of all of us on this planet

- Mitigating this set of drivers necessitates a connected, comprehensive approach; it is evident that tackling one, or another, is unlikely to have much impact by itself.

- A combination of political persuasion and technology will be required to reach any satisfactory conclusion; a comprehensive socio-technical solution will be necessary.

However, there is one slightly-hidden observation that can be made; for all interventions producing physical effects on the Drivers (mainly on the right side of Figure 1b), new devices, systems and networks will be required to remedy, replace and/or extend the functionality we have in place now, in order to address the integrated nature of the Global Drivers. Without these, we are reduced to persuasion and prayer to fix our problems.

\section{PART TWO: Sustainability in manufacturing}

As argued above, global drivers make a significant case for sustainability in manufacturing, both as a primary means to mitigate the effects of the drivers, and also because of the energy and materials demands that current manufacturing methods and processes require. Fortunately, a number of studies in recent years have addressed these issues, and a resumé of the findings is given below.

The general conclusion is that all nations in the world need to move from a 'Linear Economy' (from extraction of resources to landfill) to a 'Circular Economy' (recycling, with minimal extraction and landfill), coupled to resource efficiency. This applies to all sectors of the economy, and for manufacturing this is represented in Figure 2 below. It should be noted that other sectors will employ the products of manufacturing to turn their own linear processes into circular ones, too; this is a further justification for the concentration on manufacturing in this paper. 


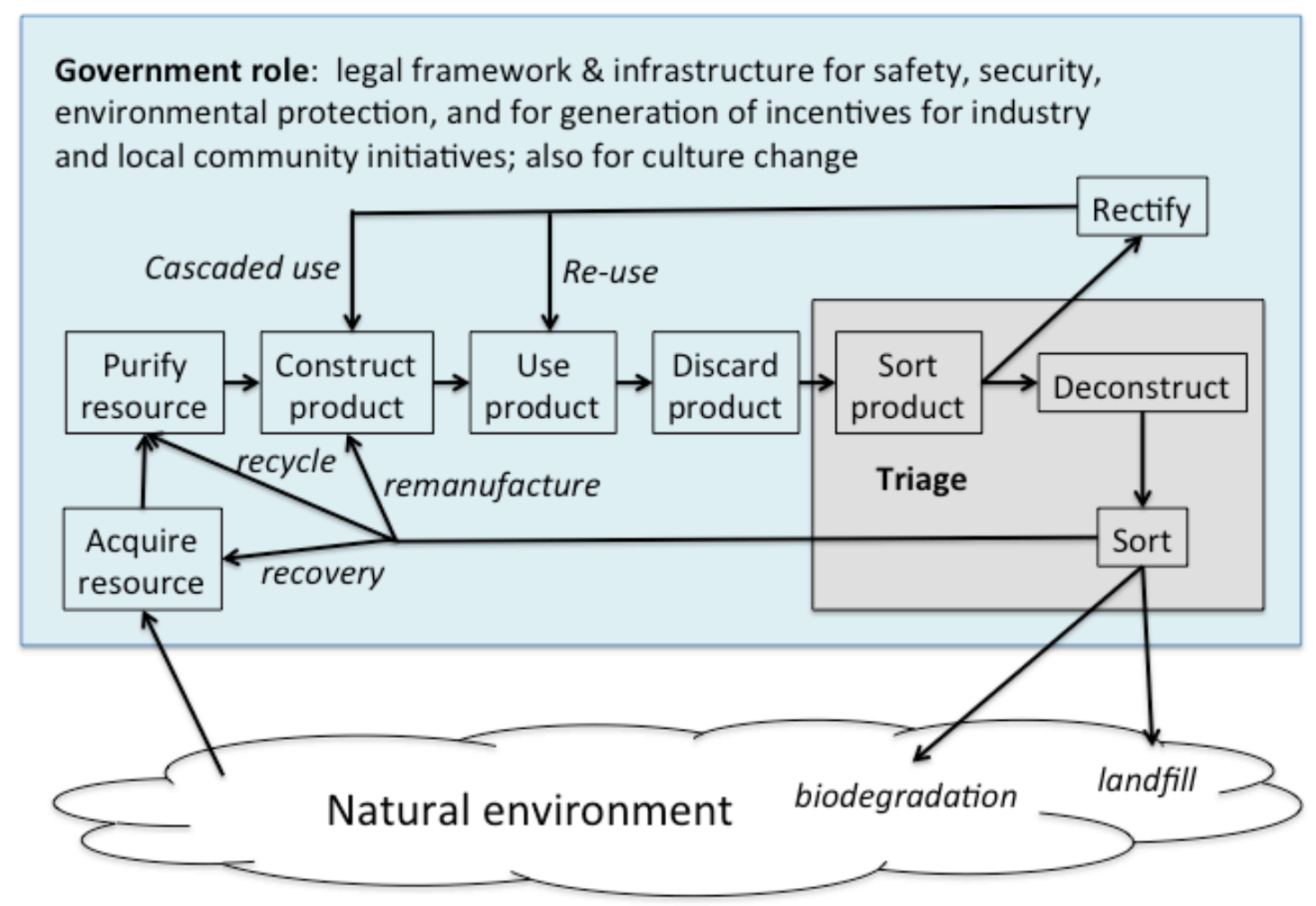

Figure 2: Illustration of 'Circular Manufacturing', as an instance of the 'Circular Economy. Linear manufacturing runs directly from the Natural environment through to Landfill.

More specifically, recycling/re-use includes the following:

- Re-use - redeploying a product without refurbishment - e.g. reselling mobile phones, 'obsolete' in the developed world in other regions.

- Remanufacturing - restoring a product to its original performance. For example, Caterpillar has a successful engine remanufacturing business (Foresight 2013, Lavery, Penell et al. 2013).

- Cascaded use - using a product for a lower value purpose - e.g. turning used clothes into pillow stuffing (Foresight 2013).

- Recycling - extracting a product's raw materials and using them for new products - e.g. aluminium and steel are widely recycled.

- Recovery - using a product's materials for a low-value purpose such as road base.

Triage, shown in Figure 2, is clearly an important process, relatively unexplored at the present time. It depends heavily on design of the product, too; 'design for disassembly' is an important principle, particularly in relation to vehicles and other products where disassembly poses dangers.

As a concrete example of this, consider the Ricoh COMET Circle, shown in Figure 3 below: 


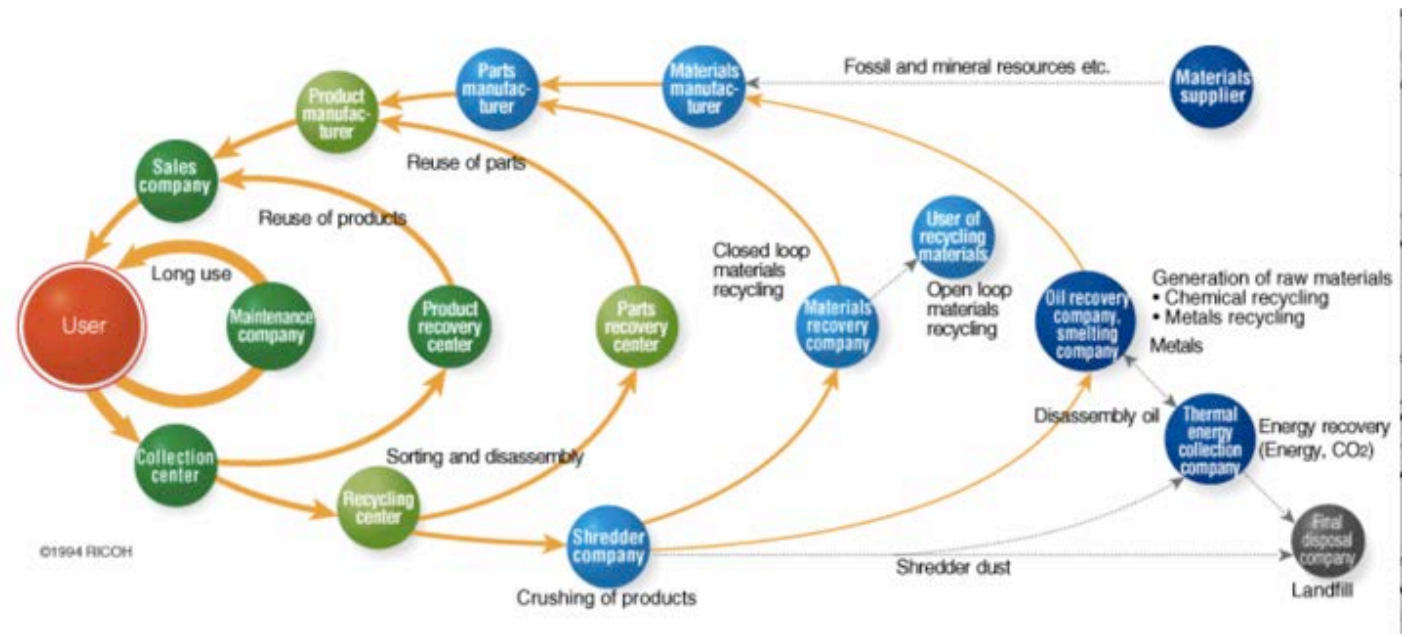

Figure 3: The Ricoh COMET Circle to recycle/ reuse photocopiers. This has resulted in a ' $90 \%$ reduction in emissions and waste'. (www.ricoh.com/environment/management/concept.html).

Ricoh has generated new companies and processes, and a new business model in which they charge by the paper copy rather than by the machine (since the copiers they supply may not be 'new'). As a further example, some other companies have claimed that they have been able to reduce waste for landfill to zero (Lavery, Penell et al. 2013).

Consider some aspects of Figure 2 in more detail, to enhance the picture:

\subsection{Extraction and utilisation of minerals}

Several reports address this issue; a sample set is (Clift and Wright 2000, Allwood, Ashby et al. 2011, Allwood, Ashby et al. 2012, Lee, Preston et al. 2012, Sulston 2012). Two common points are made; firstly, for many minerals, the cost of extraction and purification is steadily rising as a proportion of total cost, as the 'easy' sources become fully-exploited and miners must turn to lowergrade ores, and less easy to access.

Secondly, as we pass the point of 'peak availability' for a number of metals (copper being one of these; zinc is another), the cost is likely to rise considerably more (Prior, Giurco et al. 2012). Recycling is much less costly in environmental terms, and in economic terms too, since the materials remain in the circular economy. In this context, it is relevant to note that the European Commission (for example) has passed a number of directives ${ }^{1}$, supplemented by national governments, regarding manufacturers' responsibilities for waste management and which will reduce the triage problem in Figure 2. For instance, there is Directive 2000/53/EU and (2005/64/EC), both dealing with 'end of life vehicles².

\subsection{Landfill}

Many countries are experiencing problems with landfill, ranging from methane emissions from landfill sites to lack of available space. For example, in Japan, it was reported in 2008 that "Japan is experiencing a serious on-going situation in various respects: an enormous amount of waste, about 470 million tons, is

1 http://ec.europa.eu/environment/waste/legislation/index.htm

2 http://eur-lex.europa.eu/LexUriServ/LexUriServ.do?uri=CELEX:32000L0053:EN:NOT 
generated annually and, at the same time, disposal of waste is becoming more difficult ... and there is a shortage of landfill capacity at final disposal sites. As for industrial waste, the remaining capacity is 7.7 years for the entire country and 3.4 years in metropolitan areas." (MoE(Japan) 2008).

\subsection{Enterprise effects from the 'circular economy'}

Business models are involved as well, with implications for jobs; the move to a service-oriented model (as undertaken by Ricoh, for example) means that the product remains in the possession of the manufacturer, with users leasing the product. This causes many changes; to product design philosophy due to increased emphasis on longevity and reliability and lowered manufacturing cost; to choice of materials for recyclability of the product; to changes in architecture emphasising simplicity and modularity for many future upgrades. All of these changes mean changes to the jobs of the people involved; re-allocations of tasks into jobs; different co-worker relationships, new tools and techniques, etc.

An example arises from the energy requirements of domestic heating and cooling. In 2010, based on data provided by the EU Commission, energy consumption for heating and cooling was $42 \%$ of the EU27 energy budget; of this $47 \%$ was for domestic purposes; approximately $20 \%$ of the total energy budget. Renewable sources of energy replacing fossil fuels are clearly needed for sustainability reasons; but reducing demand also has a priority. This can be accomplished by a manufacturing base that not only builds the renewables infrastructure, but also creates and installs 'smart meters' and the associated information/control infrastructure inside the home and across the grid to enable end-to-end energy savings. While there may be jobs lost in the fossil fuel domain, it is likely that many more will be created in the renewables domain and in maintenance of distributed power sources, control of a more flexible grid, and provision of support to customers. Apart from the changes implied by this new technology for job design, it will be noted that many of the people working with end-users will be dealing with the elderly, perhaps with steadily declining faculties. Immediately, one can foresee that many jobs will require an ethical content, with some basic understanding of elderly needs, as well as the more technical aspects.

\subsection{Manufacturing processes}

The discussion so far points to the need for manufacturers to be frugal with their resources. In addition, there is some 'push' from legislation as indicated above, which can be quite stringent; for example there is the 'Top-runner' legislation in Japan that has been in operation since 1999 and in the EU27 the same purpose is accomplished by the ECODESIGN Directive (2009/125/EC), but from a different, lifecycle perspective.

Added to this is the usual commercial supply-chain approach, evident in automotive manufacturing, where the dominant partner, usually at the end of the chain as the assembler of the vehicle, mandates that prices for components shall drop by $\sim 3 \%$ annually for the duration of the contract, together with quality improvements. 
The standard response to all of these requirements has been by incremental process improvements, allied to occasional, usually-pre-planned, upgrades to both the products and the processes, both based on good engineering and management knowledge, sprinkled with good tacit knowledge from the workforce. However, the added constraints caused by the need to respond to the reduced energy and emissions demands of sustainability imply a significant shift to better, more detailed, control of processes and products. The introduction of new technologies such as cyber-physical systems for sensing and control, new technologies such as additive manufacturing, new materials such as graphene, alloys and ceramics, and new manufacturing concepts such as the fractionated, networked factory, distributed geographically, make a combines contribution to better control. All of these, it should be noted, will involve multiple knowledge contributions of many kinds from many people. A convenient, useful document discussing these approaches is (Kagermann, Wahlster et al. 2013).

Some aspects of efficiency in manufacturing are addressed below.

\subsubsection{Additive manufacturing to replace subtractive manufacturing, where it is cost-efficient.}

This refers to what has in the past has been termed '3D printing', in which the process uses as little material as possible to form the product, contrasted with subtractive manufacturing where unwanted material is machined away from an ingot to leave the finished product.

Particular advantages of additive manufacturing are the low forces involved, the complexity of the parts that can be produced (meaning that fewer parts may be needed to form the product), coupled with reduced energy usage in their construction, and the relative ease in producing customised parts for individual consumers (hip joints, helmets, etc.). Some disadvantages are that for precise surfaces on a component, further machining will likely be required; the process is most cost-effective for small numbers of components; there is still a lack of standards and standardisation in this arena; and there are still some knowledge gaps for the efficient, cost-effective usage of this technology

\subsubsection{Extensive use of information technology.}

As a specific example, the Federal Republic of Germany (FRG) has developed a programme entitled 'Industrie 4.0' based on networking ${ }^{3}$. The argument is that we are entering the $4^{\text {th }}$ generation of manufacturing: first there was the introduction of steam and mechanical production (a technical revolution), followed by the move to standardised parts, mass production and task specialisation (an organisational revolution), then the introduction of IT (technical again), and to be followed by the networking revolution, involving the 'Internet of Things' (IoT) which includes data, services and cyber-physical systems (organisational again), including intelligent machine to-machine communications, perhaps with significant autonomy ${ }^{4}$. The network, not the factory, becomes the core of manufacturing (for example, the Ricoh COMET cycle

\footnotetext{
3 http://www.bmbf.de/en/19955.php

${ }^{4}$ acatech(Ed.) (2011). Cyber-Physical Systems - driving force for innovation in mobility, health, energy and production. acatech POSITION PAPER. Munchen, acatech.
} 
in Figure 3 would be hard to achieve without extensive networking). Figure 4 envisions the scope of the IoT.

\section{Intelligent Interactions in 2020}

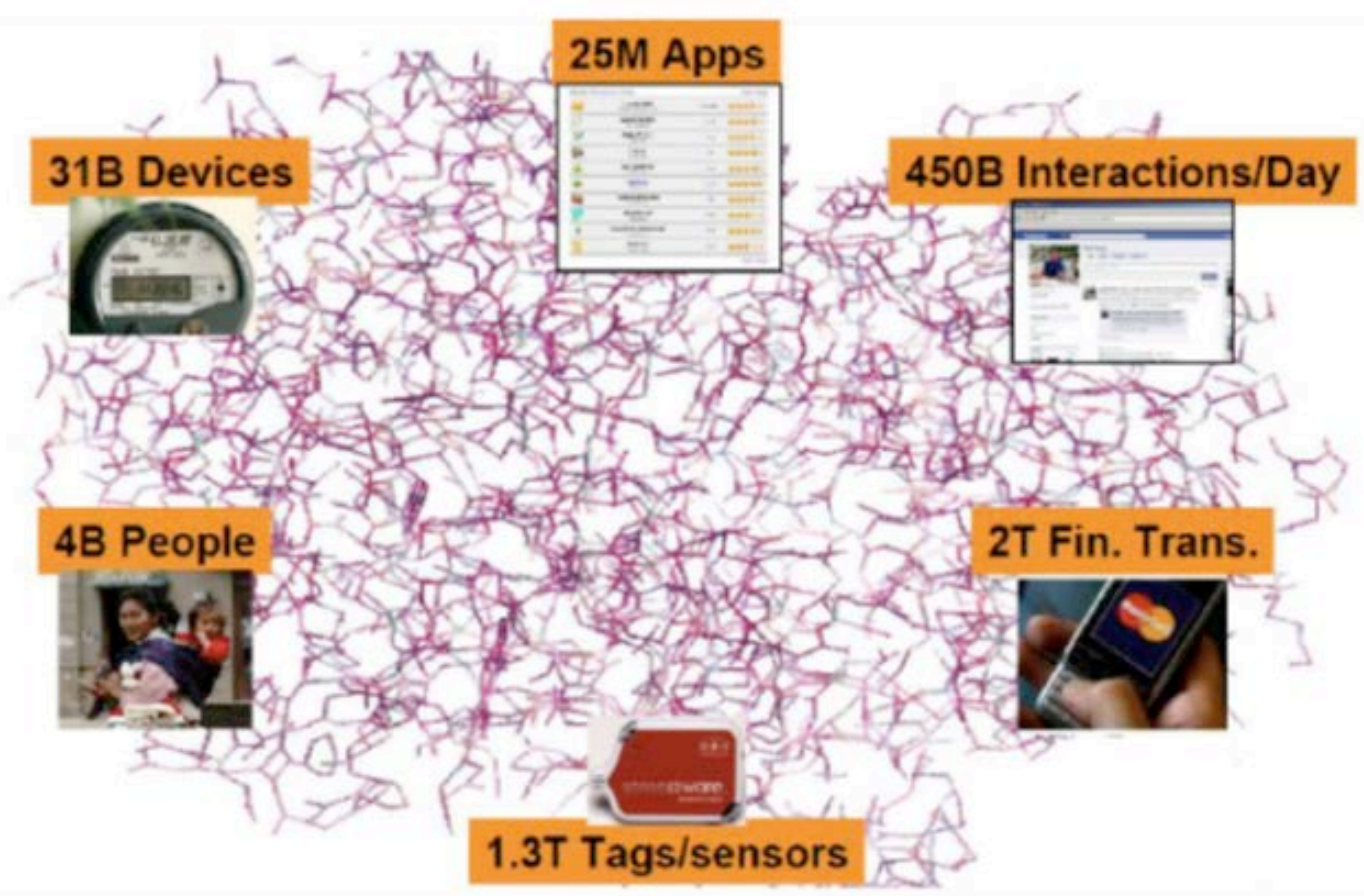

Source: IDC, 2011

Figure 4: An illustration of the expected volume of transactions of the 'Internet of Things', of which a significant percentage will be within the manufacturing domain, and supplied by it (CERP-IoT 2009, Pétrissans, Krawczyk et al. 2012).

Figure 5 below illustrates how the networking involved in the IoT might function. In anticipation of the discussion later in this paper, it is pointed out that the Virtual Objects in Figure 5 may be merely data stores, or they may have processing power (i.e. devices with embedded software systems communicating with the internet), both to communicate with other virtual objects and humans and to control the physical device to which they are attached. They may have further processing power, to adjust to their environment as it changes (e.g. autonomous vehicles), and they may be given significant learning capabilities to enable them to have even more autonomy.

These aspects regarding autonomy and learning apply even more so to the Composite Virtual Objects (CVOs.). At this level, the processes for co-ordinating and controlling these virtual objects (termed 'middleware' by the software community), there can be significant software resources for connecting sensors and actuators, for co-ordinating of the behaviour of the virtual objects within the $\mathrm{CVO}$, for communicating and negotiating with other CVOs, and for interpreting and executing strategy emanating from the machinations of the Business Application Suite. In a stable environment, the decisions of the middleware may be made by rule-sets, established during the Design and Implementation phase for the CVO. In a dynamic, non-repetitive environment it is more likely that there 
will be a significant involvement of Artificial Intelligence and Machine Learning, likely with some guidance from people. Further discussion of CPS and jobs will be found in Part 3 below.

When CVOs are combined together by a business application suite, so that the strategic goals of an entrepreneur can be turned into sequences of required behaviour, we have a simple Cyber-Physical System, necessarily involving human interaction, but accomplishing most tasks automatically and with a substantial degree of autonomy. Cyber-Physical Systems (CPS) are discussed in more detail in Part 3, below; a definition of Cyber-physical systems follows, taken from the HYCON $2^{5}$ project:

"We here take the concept of cyber-physical systems as meaning large complex physical systems that are interacting with a considerable number of distributed computing elements for monitoring, control and management. The elements of the physical system are connected by the exchange of material, energy, or momentum while the elements of the control and management system are connected by communication networks which sometimes impose restrictions on the exchange of information. ...

Cyber-physical Systems of Systems are cyber-physical systems which exhibit the features of systems of systems:

- Large spatially distributed physical systems with complex dynamics

- Distributed control, supervision and management

- Partial autonomy of the subsystems

- Dynamic reconfiguration of the overall system on different time-scales

- Possibility of emerging behaviours

- Evolutionary engineering, extension, improvement of the overall system."

Self-evidently, this is a description from an engineering perspective, in that it ignores any human involvement; nevertheless it infers many roles for humans.

5 http://www.hycon2.eu 


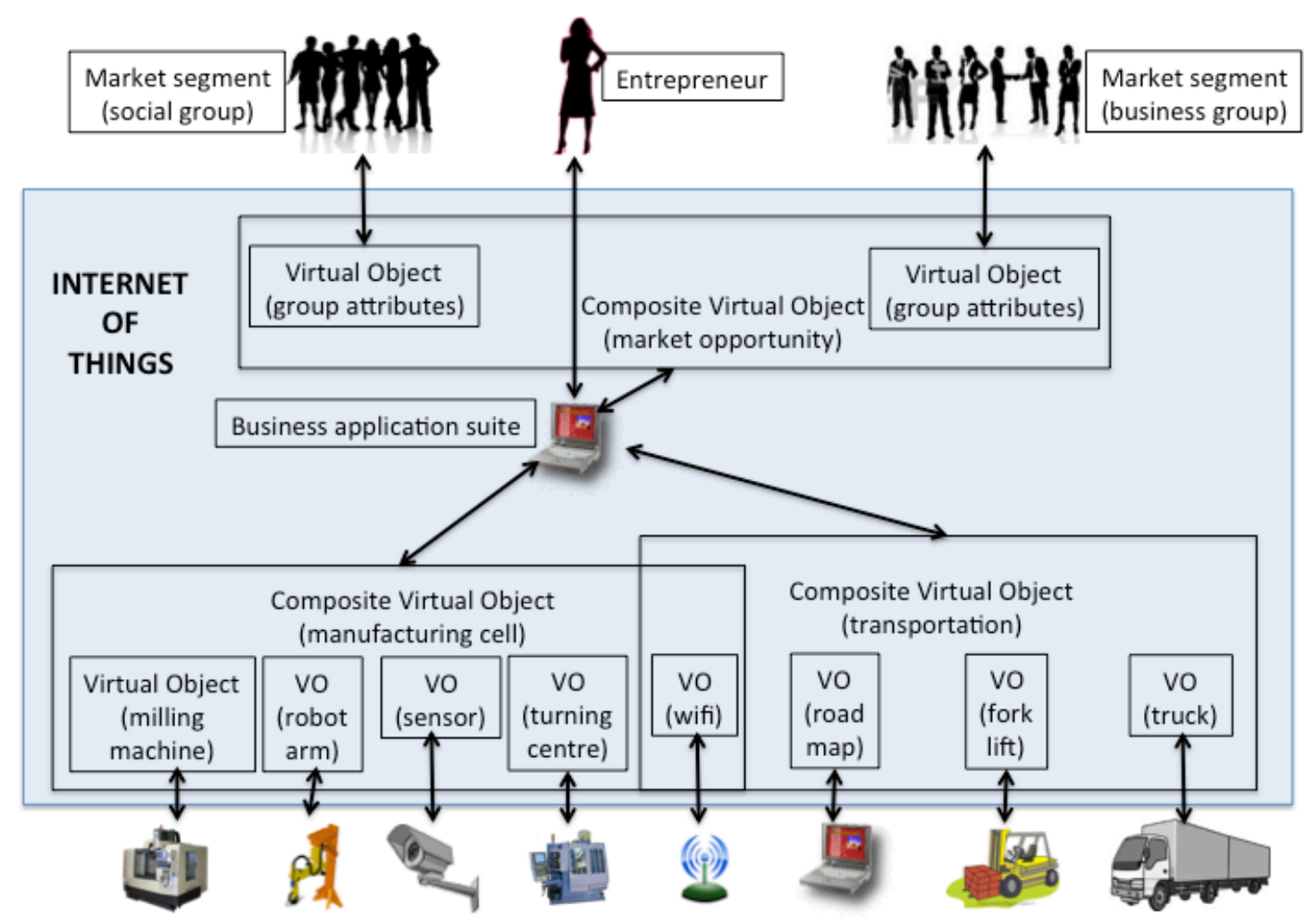

Figure 5: Illustration of the Internet of Things from a manufacturing perspective, omitting most of the complexities such as standards, interconnection protocols, interoperability contracts, co-operation and co-ordination and network security arrangements. Diagram based on the CREATENET project (Vlacheas, Giaffreda et al. 2013)

The discussion above is not predicated on large companies alone; the 'simple CPS' mentioned above could be a Small- or Medium-sized Enterprise (SME), employing a few people and with a modest annual turnover. It can then join other companies in long-term or very short-term relationships to create very large CPS; but only if its models, processes, procedures, and the semantics of its business match those of its partners. Naturally, cyber-security issues such as authentication, certification, ownership and responsibility, encryption, confidentiality and privacy, will be of great concern.

\subsubsection{Reskilling of the workforce.}

All national programmes akin to the FRG's 'Industrie 4.0' programme (for example, the UK 'Future of manufacturing'; in France, 'La Nouvelle France Industrielle') emphasise the importance of people in this networked manufacturing environment. The new approaches, whether in business models, enterprise networks, new materials and/or processes, all mean that jobs will change; however, these changes do not replace the human attributes of realworld knowledge, wisdom and experience, nor do they replace the human capacity for resilience in the face of both expected and unexpected change. They do emphasise the importance of particular skills in IT, particularly in modelling and simulation, in problem-solving, in distributed team-working, and the like. These skills must be distributed across the organisation's workforce, including managers, professionals, operators, and apprentices. This appears to be an 
implicit recognition that moving to the network will not remove problems; it may solve some, but it will redistribute the rest, and perhaps introduce some new ones.

\section{PART THREE:Implications of the discussion for the practice of Systems Ergonomics.}

\subsection{Characteristics of CPS relevant to Systems Ergonomics}

If we must be sustainable in our habits, tool usages and processes, and if manufacturing in particular is to deliver the means to be sustainable, then there is a requirement for systems ergonomists to help in the creation of products, processes, organisations and infrastructures that will service sustainability. Two quotations from Industrie 4.0 illustrate this:

"It is very likely that the nature of work in Industrie 4.0 will place significantly higher demands on all members of the workforce in terms of managing complexity, abstraction and problem-solving. Employees will also be expected to be able to act much more on their own initiative and to possess excellent communication skills and the ability to organise their own work.",

and

"It is likely that their role will change significantly as a result of the increase in open, virtual work platforms and extensive human-machine and human-system interactions. Work content, work processes and the working environment will be dramatically transformed in a way that will have repercussions for flexibility, working time regulation, healthcare, demographic change and people's private lives. As a result, in order to achieve successful integration of tomorrow's technologies they will need to be smartly embedded into an innovative social organisation [within the work-place]. " (Kagermann, Wahlster et al. 2013), bracketed words added.

The rationale here can be expanded; it is driven by the sustainability argument (particularly energy-saving, renewables and materials recovery), by legislation (for example, the ECODesign directive, and the Directives on the treatment of wastes) and by the role of networks (particularly the IoT) for organisations to maintain a competitive position in industry. In passing, it should be noted that CPSs are not restricted to the world of manufacturing; they will also pervade health care, smart cities, transport, agriculture and other domains as well.

A brief but excellent synopsis of CPS (Schätz 2014) makes many relevant points. The most important is that these systems are a paradigm shift for Systems Engineering (and by extension, Systems Ergonomics) because of three attributes:

- they are large-scale and demand a cross-disciplinary approach beyond the usual engineering disciplines, 
- they are frequently mission-critical for both systems and system of systems performance; they may extend across organisations, and cannot be switched off, and

- because of these two attributes, they must include their own engineering tools and knowledge to enable upgrades and to recover from unwanted or undesirable states.

These points imply:

- a large range models of different domains, disciplines, and technologies are used, and they may not be fully interoperable

- the use of models is extended from the design and implementation phase into the operation and maintenance phase, requiring operators and other stakeholders to be competent in manipulating these models and tools for understanding and control of the CPS; models for the control of devices, models for management and co-ordination in the middleware layer, and models at the strategy level to make sure that commands do not have unwanted consequences. As (Schätz 2014) says, "Furthermore, since CPS can autonomously reconfigure or adapt their behaviour, especially models of their platform and functionality, [they] must be made explicit at runtime. As a result of this shift, not only the construction of these models, but also corresponding analysis and synthesis methods must be made available during operation and maintenance, turning a CPS into its own engineering and development environment.".

Unfortunately, this scenario is made more complex when several companies are joined together to create a CPS. Under these circumstances, it is unlikely that there will be a unitary, hierarchical system of control; each participating organisation will maintain control of its own operations, subject to contracts that may exist between the partnering organisations. In other words, a system of federated control applies, bringing with it issues of Intellectual Property Rights, commercial confidentiality, and trust. The first two of these are business issues, and typically have the effect of preventing full transmission of important, currently-valuable information (Whitworth and Moor 2003, Siemieniuch and Sinclair 2012, Siemieniuch and Sinclair 2014, Siemieniuch and Sinclair 2015). The third is mainly concerned with the future behaviour of organisations and the humans within them, and is a matter of direct concern for Systems Ergonomics, in the form of organisational design and culture, and in job design. In the context of CPS, we may need to extend trust to include trust in software, trust in the behaviour of devices, and, interestingly, the level of trust that autonomous devices (robots, for instance) can have for their human co-workers. The latter is an issue not normally encountered in Systems Ergonomics, but one with which it will have to deal in the near future.

This section discusses some of the implications of this argument.

\subsection{Implications of CPS characteristics for Systems Ergonomics}

The first point to make is that the core principles of systems ergonomics remain the same - the socio-technical principles as enunciated, for example, by Cherns do not alter (Cherns 1976, Cherns 1987). For convenience the original set is 
summarised below.

1. Compatibility of roles with goals - ensure that role goals are clearly aligned with overall system goals. For CPS, two critical goals are situation awareness, and operational resilience.

2. Minimum critical specification - specify only what must be specified for the role(s), and enable the role holders to adapt the role to the prevailing conditions. For CPS, this specification should include understanding of, and access to tools for, modeling and simulation, and the evaluation of the consequences of decisions. It also implies the delegation of authority to do so, and acceptance of responsibility for the consequences.

3. Incompletion - leave role boundaries flexible, to allow for changing contexts and the needs of interoperation. Resilience as mentioned above will require this.

4. Systems boundaries - be as clear as possible about these, to reduce role confusion and unwanted emergent behavior. In a CPS environment, this refers critically to the interfaces between the organisations involved in the CPS and their interoperating systems.

5. Variance control - ensure that responsibility and authority over resources for control is placed as close as possible to the source of the variance. In a CPS environment, variance may be planned, to deliver what individual customers want. However, the sources of unplanned variance may be difficult to discover and recognize, perhaps due in part to the information flow restrictions that were mentioned earlier. This will place added importance on understanding and expertise in modeling and simulation; it should be noted that the models an organization uses to for the design and control of its systems and products are likely to be interoperating with those of other organisations, but the latter will likely operate as 'black boxes'.

6. Multi-functionality - of roles, to enable the learning of wisdom and the understanding of patterns; of machines, only with care, because multifunctional machines will likely have a degree of autonomy and operate by artificial intelligence.

7. Support congruence - match role support to role requirements. This will be critical; the only chance that operators and managers will have of being sufficiently situation-aware and of having sufficient control in decision-making is by means of the support tools available in a softwareintensive environment.

8. Human needs and values - ensure that these are addressed; "if you don't feed these, they will eat you". This is still true in a CPS environment

9. Feedback - essential both for role holders and for the organisation to learn, and to interoperate with other organisatios.

These principles have been extended and re-interpreted for different domains and perspectives and as organisational thinking has changed over the years (Eason 1988, Clegg 2000, Davis, Challenger et al. 2014, Doherty 2014), and have been incorporated into standards, such as ISO 6385 'Ergonomic principles in the design of work systems', ISO 9241 'Ergonomics of human-system interaction' and ISO 18529 'Human-centred lifecycle process descriptions'. However, these documents do not take into account of the extra issues characteristic of the CPS. 


\subsection{Implications for the ergonomics of job design}

A recent review paper (Zink 2013) summarises a number of changes that will be necessary to meet the new working environment for manufacturing as described above, and that also have benefits for sustainability. A number of points are made; firstly, that changes in the design of the product to use sustainable materials will equally need job/task/process redesign; secondly that the changes in processes must also minimise waste in the job (entropy in the form of heat, emissions, and materials waste), tool redesign, task removal or simplification, task support and so on. Fortunately, a recent paper (Davis, Challenger et al. 2014) outlines a methodology to address these aspects.

A particular issue that arises is the heavy dependence on modelling and simulation that is implicit in the move to CPS and the IoT. The dispersed nature of manufacturing that is envisaged implies that the formal and tacit knowledge necessary to produce safe, effective and cost-efficient products efficiently and safely will also be dispersed. While certification may provide some level of confidence in what is manufactured and how it is made, it is almost inevitable that both legally- and professionally-mandated verification and validation (V\&V) of products and processes will have to be carried out by modelling and simulation - an extension of what is now becoming prevalent in manufacturing. This will not be restricted to engineers and business planners; it will be a required part of the job for most of the stakeholders involved, because the CPS could change at any time. This implies that $\mathrm{V} \& \mathrm{~V}$ will have to be a fairly continuous exercise. Modelling and simulation of this virtual manufacturing environment and of the end-users' likely interactions and perceptions will thus become a key means for knowledge capture, utilisation, and training, as well as for efficient, effective daily operations. The interfacing of an organisation's managers, workers and support staff to the world of modelling and simulation in order to learn and to maintain their skills and subsequent employability will become a necessary part of the systems ergonomists' expertise.

Secondly, these issues become more significant in the light of likely changes to manufacturing. The tighter control over processes likely to result from, and be allocated to, cyber-physical systems will distance workers from the work. This distancing is likely to be enhanced as the Virtual Objects and CVOs become evermore autonomous and necessarily are equipped with learning capabilities. This distancing from work will be exacerbated by the fractionation of the factory into a network that likely will remove any visibility of the continuity and integrity of the whole process. Both of these will affect situation awareness and subsequent understanding.

Thirdly, because of the ever-increasing pace of change, driven both by shorterterm drivers of competitive advantage (particularly in relation to 'mass personalisation' - "no two products are the same") and by the longer-term needs of the sustainability agenda, there is an issue of 'human workability' (Ilmarinen 2006, Docherty, Kira et al. 2009). This is defined as individuals and teams having the health, physical, psychological and social functional capacity to do designated work, including professional competence, values and ethics, and understanding of work conditions, work community, supervision, and the characteristics and processes of change. 
As a specific instance, the demands of resilience in the workplace (e.g. for personalised products, for problem-solving, for rapid changes in production plans) will require immediate communications. One can foresee an important role for IT tablets (or similar devices) to provide mobile real-time situation awareness (a prerequisite for resilience), both to keep operators informed, to provide task support, and to provide fast feedback to other functions. This has significant implications for the design of the IT infrastructure to support such jobs and their support devices. It is possible that problem-solving might require communication across a global network, even for small problems; hence much of the ergonomics work already undertaken in earlier years on computersupported co-operative working will be applicable to this, though perhaps requiring a little updating. Furthermore, there is an obvious need for a competent, empowered workforce in trusted relationships if such processes are to succeed.

Thirdly, 'workability' in relation to change entails considerations of 'employability'. This includes an individual's ability to gain and maintain employment, to move between roles within an organisation, to obtain new employment in an equivalent role, and to be equipped with the knowledge and skills to do so. Since the latter applies across all employees, employers have a role to play in ensuring collective learning as well; it becomes an organisational skill, particularly in imparting the skills of sustainability. While people may learn these skills in the workplace, the thinking involved will be useful in other aspects of their lives. This takes on added importance when one considers that this new manufacturing environment places a premium on knowledge work; there may be an appreciable diminution of jobs available for semi-skilled workers and managers; ensuring that they are employable in other spheres and jobs will be an important consideration.

Fourthly, there is the necessity of turning the principles of Corporate Social Responsibility (ISO26000 2010, UNHRC 2011), including those of Responsible Research and Innovation (E. Palmerini 2014, RRI@Rome 2014) into the tasks and roles that people undertake every day. As an initial step, the principles must be translated into Key Performance Indicators (KPIs) appropriate to the performance of the organisation in relation to these policies, and then these must be cascaded down into the activities (i.e. Activity Performance Indicators - APIs) that people undertake within their roles. Following the socio-technical principles enunciated by Cherns and others, they may have to become part of the Minimal Critical Specification for a role. Given this, the role-holder will require training and authority over resources to be able to achieve these APIs. Given the range that these APIs may take, the organisation may well have to have very good links into local education and training facilities, professional services and the like in order to fulfil its obligations to the role-holder.

Finally, from an ergonomics perspective, all the issues mentioned above are replete with the complexities arising from the fact that people are individual in their hopes, aspirations, and personal histories. What we as ergonomists normally call 'job design' with its emphasis on health, safety, satisfaction and performance will need some reconsideration. 


\subsection{Whole systems approach}

While ergonomics practitioners are skilled in systems ergonomics, there is a requirement for extension of this into systems of systems ergonomics, since CPSs have extra characteristics not evident at the systems level (see section 3.1 above), such as the interoperability issues consequent upon linking independent systems together (Maier 1998, Dahmann and Baldwin 2008, Jamshidi 2009b, Firesmith 2010, Barot, Henson et al. 2012, Henshaw, Barot et al. 2013). A major consideration in the CPS and systems of systems environment is emergent behaviour, frequently intended and beneficial, but also unexpected, unpredictable and detrimental. The latter come about firstly because of the more extensive boundary between the CPS and their external environment, but also because of the internal environment, for example, a single organisation within the CPS may change its system for better internal performance within the organisation, without being aware of consequent knock-on effects elsewhere in the SoS (Siemieniuch and Sinclair 2014).

For systems of systems ergonomics as applied to CPS, there is a strong requirement for resilience and agility to be designed into the CPS, as well as the usual goals of efficiency and cost-effectiveness. There is an interesting dilemma in this; the trend to assign more capability to the automation and autonomy within cyber-physical systems may work against resilience and agility. As a result, humans as the main source of these attributes may lose the knowledge and skills to be able to act as the drivers of resilient and agile action, when this is likely to be their most important role from time to time.

There is an added complication; the CPS is likely to be held together by a network of contracts, firstly to ensure the delivery of products and services in an efficient manner and to receive payment for these products and services, and secondly to formalise how authority, responsibility and ownership is distributed within the CPS for all the transactions involved. The latter, as a consequence, also allocates liabilities. It should be noted that a contract in the world of CPS may well have effects beyond those organisations that signed it, because of the constraints contained within.

This introduces a wider range of issues for resilience, in which the sociotechnical principle of 'minimum critical specification' as outlined in Cherns and others (op. cit) becomes important in the writing of contracts, to leave room for people to organise ways round any unexpected problems, as indicated in the section on job design. The implementation of this criterion may require some care, in view of the liability aspects implied above.

A different approach to safety may be required too; the 'old' approach of finding the cause of an anomaly and fixing it so that the process is back where it was, and then writing a procedure to ensure the anomaly does not recur is unlikely to be sufficient in this new world of co-operating but independent systems. More useful would be to look also at what is going right and then build on this, thereby reducing unpleasant surprises. This approach is described as moving from Safety-1 to Safety-2 (Eurocontrol 2013); there is some overlap with the theorising behind the 'High Reliability Organisations' approach (Rochlin, LaPorte et al. 1987, Weick and Roberts 1993, Roberts and Bea 2001) and of 'Resilience 
engineering' (Leveson 2004, Hollnagel, Woods et al. 2006, Dekker, Hollnagel et al. 2008).

To elaborate the CPS context further, consider a classification of interoperability levels within a system of systems (NCOIC 2011), shown in Figure 6.

Interoperability of two or more systems depends on the co-alignment of the interfaces between them, and NCOIC has defined a number of levels to enable thinking about interoperability. The top five layers are those of most interest to systems ergonomists. When one considers the global reach of CPs in any domain, let alone manufacturing, with different cultures, different legal systems, different time zones and so on, there is clearly a need for an extended toolset and methodology for ergonomists (and other cognate disciplines) to use in the pursuit of interoperability goals.

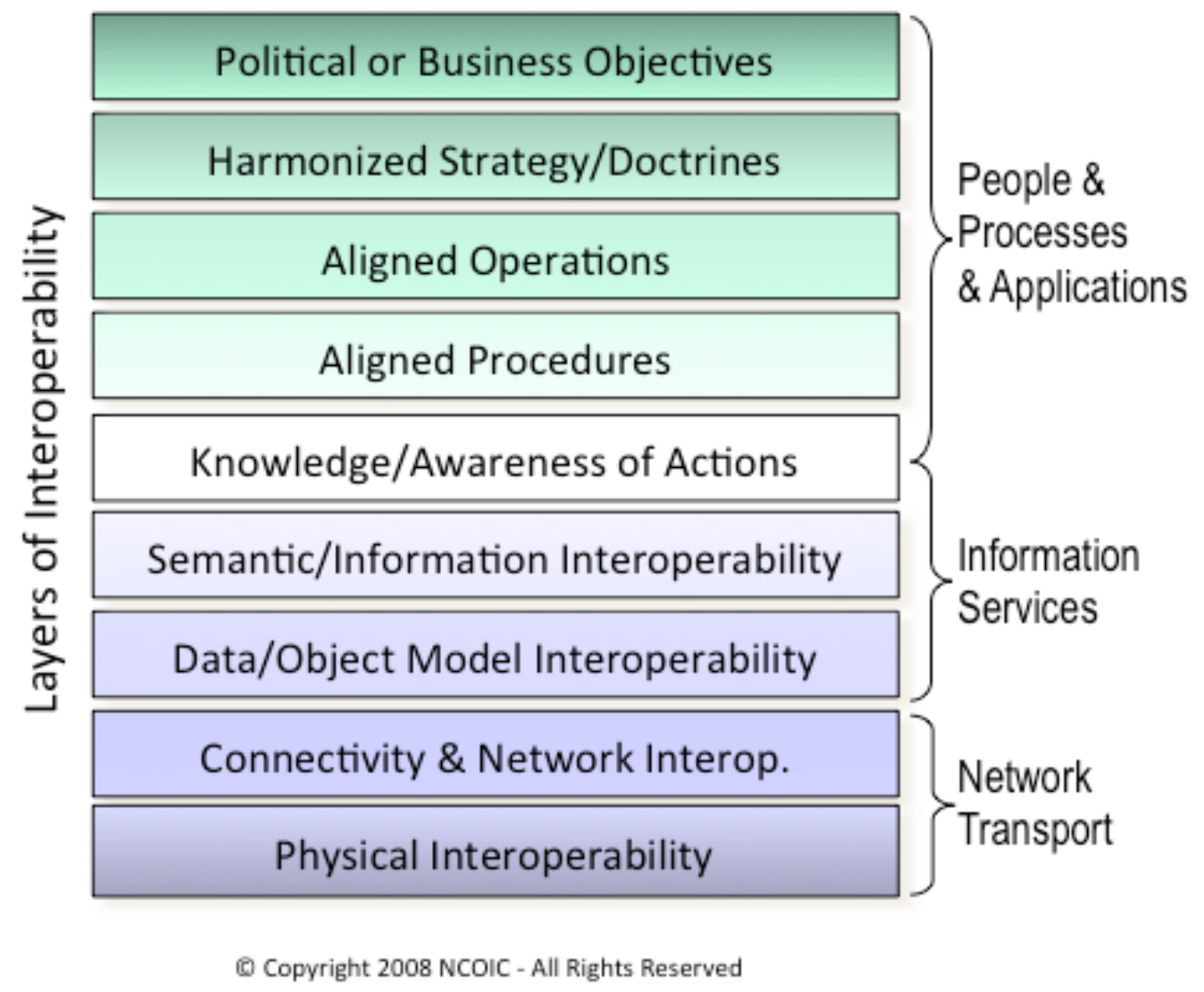

Figure 6: NCOIC operability layers, 2008 version. While the bottom layers are essentially technical (albeit supervised by humans), it is the top five levels that are of most interest for systems ergonomists.

Fairly swiftly too, it follows that there will need to be a focus on revision/extension of standards, particularly in the following three areas:

1 Assuring the quality of products by standardising the product itself

2 Standardising and certifying the processes used to make the product. In a networked world, this will involve semantics and ontologies for communications across disciplines and professions, reference architectures, and technologies for debugging and tracing, risk and liability assessment, and safety and security. 
3 Addressing the principles and values that sustain the successful organisation of supply chain. These are issues affecting the underlying culture of the organisation - attitudes to health \& safety, to risk management, contracts, leadership, boardroom behaviour, motivation, and organisational behaviour

It is mainly the second and third areas which will require attention; for instance in witness to this, several standards bodies around the world have commenced work on standards for the 'Smart City', in which it is expected that about 70\% of the world's population will be living by 2030 .

\subsection{Organisational change and modelling}

As implied in the discussion above, there is a large degree of organisational rearrangement and redistribution of roles, authority, responsibilities and skills involved. Inevitably there will be associated organisational culture changes to be carried through as well; as a manager commented when involved in an organisational shift to a service orientation (similar to Ricoh),

"Basically [we] spend [time] explaining to people some of the new skills that we need and some of the new mindset issues about, for example, spares always used to be a profit opportunity; now they're a cost, and that's a completely 180 degree turn for us" (Johnstone, Dainty et al. 2008).

There is an evident role for ergonomics skills in accomplishing this kind of shift in organisational cultures, but these skills need the extra knowledge base about systems of systems to make the skills most effective; these skills fall into the top two levels of the NCOIC framework in Figure 6, and there is little point in just one company making such changes if the others in the CPS neither recognise them nor accommodate them.

It has been mentioned several times above that, given the scale of change that likely will be required and the possible extensive consequences thereof, there is a strong requirement for modelling and simulation tools and methods. There is something of a lacuna in this area (Henshaw, Barot et al. 2013), though it is hoped that some EU projects (e.g. COMPASS ${ }^{6}$ and DANSE ${ }^{7}$ ) will address this gap in the near future.

\subsection{Human in the loop for decision making}

As stated above, because the organisations in the network (including the cyberphysical systems, other devices and data sources that they own and to which they provide access) may change their behaviour and functionality without much warning, and because some information may be precluded from transmission for reasons of commercial confidentiality and security, the goals of ensuring that processes and systems are resilient and agile will be as important as efficiency, effectiveness and energy conservation. This will place an emphasis on humans being 'in the loop' to provide resilience and agility, with consequent demands for training in awareness, problem-solving, and execution skills, as said above. However, as stated above, the growth of cyber-physical systems within the IoT

\footnotetext{
6 http://www.compass-research.eu

7 http://www.danse-ip.eu/home/
} 
(for example, smart meters, autonomous transport, introduction of robots as coworkers, etc.) may mean that humans are removed from in-the-loop activities to supervision; 'on-the-loop' activities, endangering the close knowledge and skills necessary to enable deft exercise of resilience.

This area also abounds with difficulties, particularly for the humans entrusted with problem-solving skills to address surprises, restore desired functionality, and to do so with agility. Given figures 4, 5 and 6, how is any human to find and fix any complex or subtle issues? In relation to the $V \& V$ problem mentioned earlier, one can foresee the need for the network to have elaborated versions of Built-In Test Equipment (BITE) (Fowler and Silver 2014) and for extensive system health monitoring systems (Merkle, Middendorf et al. 2008, Takewaki, Nakamura et al. 2011). This will certainly make diagnostics easier at the lower levels of the NCOIC framework (see Figure 6), but at higher levels of the Framework where externalities, semantics, ontologies and legalities become significant, it is probable that humans will have a predominant role, albeit with the use of support tools. Then there comes the problem of fixing any fault without causing any further problems; again, recourse to simulation and modelling will be required.

Consider, for example, first-, second- and third-loop learning (for reference: firstloop learning involves acquiring the skills to improve and polish process performance skills for greater efficiency and reliability; second-loop learning enables internal process improvements equivalent to those provided by Quality Circles, and third-loop learning enables answers to strategic questions such as "'Why are we using this process? Do we have to do things this way?"). If the network is capable of first-loop learning (e.g. mapping and reporting currentlycontracted process and data paths used by the CPS through the network), then tracing and fixing problems might be tractable. If second-loop learning is allowed (e.g. cyber-physical systems within the network are allowed to redirect data flows to alternative nodes to 'improve' performance, then small semantic differences at these new nodes may induce subtle problems that are difficult to track and fix). Third-loop learning, where in principle the network can ask, answer and act on questions such as 'Is there any real value for the network in doing this?' may render human problem-solving almost impossible because of the difficulties of elucidating AI-based decision logic.

\subsection{Understanding and modelling the impact of culture on resistance to change}

There is likely to be a knowledge and culture upheaval in the design and engineering parts of the organisation, both to redesign products, to incorporate recycling considerations, to creating new processes and their associated technology, and to creating new jobs. For all of these, there is a role for ergonomics knowledge and skills (especially in the light of creating 314,000 new jobs in the UK alone).

Concomitant with these changes, there will be necessary changes to the culture(s) of the customers of these manufacturing organisations. Where the customer is another business, there may be fairly small issues to address; however, consumers in general are a different matter. While government 
legislation, from the European Commission downwards, will create both incentives, disincentives and educational programmes to induce consumers to shift to sustainable practices and beliefs, it is likely that there will be a need for ergonomists/ human factors engineers to be more proactive in considering steps to nudge consumers, as end-users, to adopt new practices. This may not be easy; for example, consider the emotional and cultural barriers in encouraging consumers to alter their eating habits and to reduce food wastage.

An example of cultural changes as organisations mature is given in 7.

New-Market-Driven

Commercialisation

Figure 7: Illustration of the changes in culture (bold type) that occur over the life-cycle of an organisation in manufacturing. A start-up company at the left of the figure migrates by either the top, middle, or bottom route to and end-state, assuming it survives beyond a technology wave. (Gover 1993).

As Figure 7 implies, there must be some kind of match between the operational environment, the structure and policies of the organisation, and the team cultures of those who work in the organisation. Useful discussions can be found in (Mantovani 1996, Tannenbaum, Salas et al. 1996, Hodgson, Hubbard et al. 2013).

\subsection{Ethical design and operation issues for Systems Ergonomics}

There are some deep ethical issues that we as ergonomists/human factors engineers cannot ignore in this context. Five in particular stand out. These all stem from the role of humans both as customers of the network and as controllers of networked processes, in which semi-autonomous, cyber-physical systems play a part.

- 'Informed Consent'; for example, you give consent to a request from the network to use your current location data. It is unlikely that you know, or ever could know, who or what has access to that data, for how long this 
access will be enabled, how your data will be combined with other data, what meaning(s) will be inferred from the data, which organisations will 'own these data, and so on. This is self-evidently a design issue for systems thinkers in general, and Systems /SoS Ergonomists in particular. Solutions are not immediately evident, tough it is good news that the US Senate is developing a bill to regulate the activities of data-broker organisations (Senate bill S. 668).

- 'Informed Command', as given, for instance, by a human controller involved in a networked process in which some devices may have some degree of behavioural autonomy - cyber-physical systems being a prime example of this. The UK Ministry of Defence has a rule of for this; summarised as 'whoever gives the last command is responsible for the outcomes.' This is also embodied in International Humanitarian Law. The implication is that whoever gives a command must be able to anticipate the likely outcomes and side-effects of any command. This, of course, presumes that the command-giver can evaluate the likely outcomes, and if surprised, can alter the command in time. It is not obvious how any command-giver in the context of the IoT, let alone manufacturing, could be sure of the outcomes, especially if these outcomes are at a distance from the command-giver; in a different environment, in a different culture, in a different legal framework. Again, solutions are not immediately evident; nevertheless, this problem sits at the heart of systems of systems/SoS ergonomics.

- Identity. As a Foresight document has pointed out, each of us has many identities, and some of these are not constructed by us but exist on the internet (Foresight-FFI 2013). There is a question of who owns and who can use these identities and for what purpose, especially those we have not constructed ourselves. This has implications for the notions on informed Consent and Informed Command, above, especially if some of these identities have been created or utilised with criminal intent.

- Autonomy and learning. Not all CPSs need to be given the capability to learn, though many must; robots, for instance, and middleware that cannot rely solely on sets of pre-established rules. As discussed above, learning can be of 3 types; first loop, as in the robot learning routes from A to B; second loop as in finding ways to shorten or speed up the routes; or third loop where the robot devises answers to a question like 'should we be doing this?'. First loop learning may not be a problem within a network; second loop learning could be a problem because the agents may change their behaviour in ways not expected and may change their communication links. Third loop learning will be a problem; in extreme cases, the network may decide to omit you as a command-giver from the process because you have made mistakes. Current thinking suggests that autonomy should be constrained to level 6 or below on Sheridan's scale for autonomous operation: 'The [robot/ computer/ software] allows the human a restricted time to veto [the proposed action] before automatic execution" (Parasuraman, Sheridan et al. 2000); however, this returns the problem to 'Informed Consent' and 'Informed Command'; the level 6 rule assumes that the command-giver is in an appropriate 'informed' state. 
- Many humans giving many commands to a CPS. One possible scenario arises in the context of a smart city; it has a CPS that communicates with vehicles and their drivers, and controls all traffic lights in the city, to optimise journey times for all drivers. Assume an emergency arises, and police vehicles are called to provide assistance. The CPS arranges the traffic lights to display green lights for all the routes of vehicles attending. However, trying to get to a hospital across these routes is an ambulance with several very ill people on board, also calling for a green light route. In principle, the middleware is now faced with an ethical decision (though in this example there may be enough degrees of freedom to minimise the ethical considerations). Other scenarios can be envisaged in which ethical issues will arise for many CPSs, often created by many humans interacting within a single CPS. The design of a distributed interface for this scenario, exhibiting ethical decision-making that is capable of being trusted by its multiple, individual users, is an open, complex problem for systems ergonomics. Likewise, there will be ethical issues in decisions made by the CPS and affecting large numbers of customers, all of whom are individual with different needs and goals.

\subsection{A summary of added knowledge requirements for the practice of systems ergonomics in the future}

While these high-level requirements have arisen from a consideration of manufacturing, they are also applicable to other domains as well, in which CPS may be employed. There is a presumption in most of these requirements that systems engineers and systems ergonomists will be working collaboratively; the engineers will deliver CPSs, while the ergonomists attend to the quality of the human-system interfaces, both within each component system and at the interfaces between them. A list follows, aimed at a chartered member of the ergonomics/ human factors profession; it may be necessary to extend or amend this list in the future.

- An understanding of the generic architecture of CPSs, from sensors and actuators through the components and functions of middleware, to the business applications that set goals and drive the CPS. This understanding should include some experience of CPS precursor systems that exist now, to prepare practitioners for the advent of complete CPS.

- A good understanding of the theory of Model-Based Systems Engineering (MBSE) as a knowledge basis for communication with system engineers as they design and instantiate CPS. This should be sufficient to enable intelligent communication with systems engineers and other engineers without confusion and loss of meaning; again, some experience in the use of MBSE tools would be very helpful. This too could be obtained from current instantiations of MBSE in industry.

- A good understanding of resilience engineering; firstly, how engineers build resilience into systems; secondly, the skills and knowledge required by humans to augment this engineered resilience; and thirdly how these capabilities (including support for these capabilities) should be distributed around the organisation(s) that are responsible for resilience. 
- Extension to the principles of human-system interface design to include distributed interfaces for multiple, different users, with attention to the techniques of engendering trust in the behaviour of the interface. The issue is that the interface provides the 'face' of the system, which must enable situation awareness by providing answers to users' questions such as "what is happening?" "what is not happening?", "why are you telling me this?" and many more. Helping engineers to deliver good interfaces will be an important skill.

- Extension of socio-technical systems theory to encompass the evergreater intrusion of devices, processes, software and artificial intelligence into work and society. Because the technology of CPS for some time to come will lack human values such as empathy, compassion, social duty and care, and may never understand punishment, socio-technical systems theory as applied to job and organisation design should include principles for the allocation of authority and responsibility, and how ethical behaviour of the CPS can be assured. The latter includes aspects such as informed consent, informed command, identity, etc.; this is necessary for human co-workers in the CPs, its end-users and some other stakeholders could view the behaviour of the CPS as trustworthy.

- Development of job design to include working in distributed teams, distributed operational problem-solving involving the use of modelling and simulation facilities, on-line verification and validation of CPS behaviour, and what constitutes trust-worthy behaviour.

- Understanding of the culture of distributed team-working, of trustworthy behaviour, the acceptance of fairly frequent change in processes and jobs, and the need for continuous learning.

This is a daunting list, and for some of the requirements to be met there will have to be considerable application of intellectual effort. But the rewards for doing so are very great, both for society as a whole and for the profession itself. We hope that you, the reader, agree with this.

\subsection{Suggestions for the means to acquire and extend systems ergonomics knowledge}

The 'daunting' list' above is unlikely to be implemented without an action plan. Given below are some suggestions that might be included in such an action plan:

- Involvement of professional bodies: Given that CPS is a complex, multidisciplinary domain, it will need the attention of the ergonomics/ human factors professional societies that are members of the International Ergonomics Association to develop appropriate action plans; particularly since CPS will appear in almost all societal domains.

- Study existing systems: as a departed human factors sage often remarked, "Remember Santayana - whatever new system you are designing, there are precursor systems with histories; it is better to learn the problems before you start your work." This is certainly true for CPS; precursor and prototype systems already exist. However, access to these to gain understanding may be difficult, for commercial reasons

- Develop theoretical understanding through academic studies. An obvious action point, but there are many aspects to be developed that will 
require cross-disciplinary study. A good list of to[ics will be found in the Strategic Reseach Agenda produced by the T-AREA-SoS project (Henshaw, Barot et al. 2013) ${ }^{8}$. As this document indicates, co-operation and coordination with many other professional societies and funding bodies will be required.

- Disseminate this understanding via Continued Professional Development activities, journal articles, and the usual other channels.

- Disseminate this understanding to students: while this is necessary to provide new generations of experts, there will be obvious difficulties in fitting this knowledge extension into academic programmes. This will have effects on other areas of ergonomics knowledge, so it would appear to be another area for the professional bodies to consider.

\section{Conclusions}

The Global Drivers described at the beginning of this paper will be present for the foreseeable future, and while they are, the issues of sustainability will always need to be addressed. There are now virtual libraries of reports, papers and legislative instruments all addressing the issues with greater or lesser effect, and it is safe to assume there will be many more, as the decades roll by.

However, there is one characteristic of most of these documents; while they recognise the central importance of humans in reaching and maintaining sustainability, both as creators, operators and customers, the implications of human involvement in the socio-technical systems and processes that will sustain the world are not well addressed. Chief among these will be cyberphysical systems, because they can deliver significant benefits in addressing each of the global drivers. There is a huge and important role for Ergonomists/ Human Factors Engineers in contributing knowledge and wisdom, both in the design and operation of these sustaining systems and processes and ameliorating the undesirable effects of change on the recipients of changed processes. However, this role, wherever it is practised in the world, will require very knowledgeable people. It is not immediately evident that enough people with enough knowledge are available in the areas that this paper discusses. It seems that the professional societies that make up the International Ergonomics Association all have some work to do.

The words of Albert Einstein are relevant here:

"The world as we have created it is a process of our thinking. It cannot be changed without changing our thinking."

\section{References}

(2005/64/EC). Directive on the type-approval of motor vehicles with regard to their re-usability, recyclability and recoverability. European Union.

8 https://www.tareasos.eu/results.php 
(RRI@Rome 2014). Rome Declaration on Responsible Research and Innovation in Europe P-EC2014. European Union, Italian Presidency of the Council of the European Union.

2009/125/EC, E. (2009). Directive 2009/125/EC of 21 October 2009

establishing a framework for the setting of ecodesign requirements for energyrelated products. European Union, European Commission.

Aguirre, D., L. Hoteit and K. Sabbagh (2012). "The third billion: empowering women, powering the global economy." $\underline{\mathrm{S}+\mathrm{B}}(15$ October).

Allouche, J. (2011). "The sustainability and resilience of global water and food systems: Political analysis of the interplay between security, resource scarcity, political systems and global trade." Food Policy 36(Supplement 1): S3-S8. Allwood, J. M., M. F. Ashby, T. G. Gutowski and E. Worrell (2011). "Material efficiency: a white paper." Resources, Conservation and Recycling 55: 362-381. Allwood, J. M., M. F. Ashby, T. G. Gutowski and E. Worrell (2012). "Material efficiency: providing material services with less material production." Phil. Trans. R. Soc. A 371(1986).

Barot, V., S. Henson, C. E. Siemieniuch, M. J. d. C. Henshaw, M. A. Sinclair, S. L. Lim, C. Ncube, M. Jamshidi and D. DeLaurentis. (2012). State of the art report: TransAtlantic Research and Education Agenda in Systems of Systems (T-AREA-SoS). p. n. EU Framework Programme 7. Loughborough, UK, Loughborough University,: 126.

Batty, M., K. W. Axhausen, F. Giannotti, A. Pozdnoukhov, A. Bazzani, M. Wachowicz, G. Ouzounis and Y. Portugali (2012). "Smart cities of the future." European Physical Journal - Special Topics 214: 481-518.

CERP-IoT (2009). Internet of Things - Strategic Research Roadmap. Brussels, European Commission - Information Society and Media DG.

Cherns, A. B. (1976). " Principles of socio-technical design." Human Relations 29: 783-792.

Cherns, A. B. (1987). "Principles of socio-technical design revisited." Relations 40(3): 153-162.

Clegg, C. W. (2000). "Socio-technical principles for system design." Applied Ergonomics 31: 463-477.

Clift, R. and L. Wright (2000). "Relationships between environmental impacts and added value along the supply chain." Technological Forecasting and Social Change 65: 281-295.

Dahmann, J. and K. Baldwin (2008). Understanding the Current State of US Defense Systems of Systems and the Implications for Systems Engineering. 2nd Annual IEEE Systems Conference. Montreal.

Davis, M. C., R. Challenger, D. N. W. Jayewardene and C. W. C. a. a (2014).

"Advancing socio-technical systems thinking: a call for bravery." Applied Ergonomics 45: 171-180.

Daw, A. J. (2007). Keynote: On the wicked problem of defence acquisition. 7 th AIAA Aviation Technology, Integration and Operations Conference: Challenges in Systems Engineering for Advanced Technology Programmes. Belfast, N.I., AIAA: 1-26.

Dekker, S., E. Hollnagel, D. Woods and R. Cook (2008). Resilience Engineering: new directions for measuring and maintaining safety in complex systems, Lund University School of Aviation. 
deWeck, O. L., D. Roos and C. L. Magee (2011). Engineering systems - meeting human needs in a complex technological world. Cambridge, MA, MIT Press. Docherty, P., M. Kira and A. B. A.B. Shani, Eds. (2009). Creating sustainable work systems. London, Routledge.

Doherty, N. F. (2014). "The role of socio-technical principles in leveraging meaningful benefits from IT investments." Applied Ergonomics 45: 181-187. E. Palmerini, F. A., F. Battaglia, A. Bertolini, A. Carnevale, J. Carpaneto, F. Cavallo, A. Di Carlo, M. Cempini, M. Controzzi, B.-J. Koops, F. Lucivero, N. Mukerji, L. Nocco, A. Pirni, H. Shah, P. Salvini, M. Schellekens, K. Warwick (2014). D6.2 - Guidelines on regulating robotics Pisa, Italy, Robolaw project, EU Grant Agreement number: 289092.

Eason, K. D. (1988). Information technology and organisational change. London, Taylor \& Francis.

EC2011 (2011). The EU energy policy: engaging with partners beyond our borders.

EC-Energy (2011). Energy efficiency plan 2011. Brussels, European Commission. EC-ET (2006). Global Europe. Brussels, European Comission.

EC-Transport (2011). Roadmap to a Single European Transport Area - towards a competitive and resource efficient transport system. Brussels, European Commission.

ECecodesign (2009). Directive 2009/125/EC of the European Parliament and of the Council of 21 October 2009 establishing a framework for the setting of ecodesign requirements for energy-related products (Text with EEA relevance). O] L 285, 31.10.2009, p. 10-35. European union.

Eurocontrol (2013). From Safety-I to Safety-II: a white paper. Bretigny sur Orge, France, European Organisation for the Safety of Air Navigation: 30.

Eurostat (2011). EU27 population is expected to peak by around 2040. Eurostat. Brussels, Eurostat Press Office: 2.

Firesmith, D. (2010). Profiling systems using the defining characteristics of Systems of Systems (SoS), SEI, Carnegie-Mellon University.

Foresight (2013). The future of manufacturing: a new era of opportunity and challenge for the UK (Summary report). London, The UK Government Office for Sciece.

Foresight-FFI (2013). Foresight Future Identities (executive summary). L. The Govenment Office for Science. London, The Government `office for Science.

Fowler, K. R. and C. M. Silver (2014). Developing and managing embedded systems and products: methods, techniques, tools, processes, and teamwork, Newnes.

Gover, J. E. (1993). "Analysis of US semiconductor collaboration." IEEE Transactions on Engineering Management 40(2): 104-113.

Guitink, P., S. Holste and J. Lebo (1994). Non-motorized transport: confronting poverty through affordable mobility. Washington, DC, The World Bank.

Gutowski, T. G., S. Sahni, J. M. Allwood, M. F. Ashby and E. Worrell (2013). "The energy required to produce materials: constraints on energy-intensity improvements, parameters of demand." Philosophical Transactions Royal Society series A $\mathbf{3 7 1}(1986)$.

Henshaw, M. J. d., V. Barot, M. A. Sinclair, C. E. Siemieniuch and S. Henson (2013). Common Vision and Strategic Research Agenda (Work Package 5, Deliverable D5.1). Loughborough, UK, Loughborough University. 
Hodgson, A., E.-M. Hubbard and C. E. Siemieniuch (2013). "Toward an understanding of culture and the performance of teams in complex systems." IEEE Systems Journal 7(4): 606-615.

Hollnagel, E., D. D. Woods and N. Leveson, Eds. (2006). Resilience engineering. Aldershot, UK, Ashgate Publishing Ltd.

IEA (2010). Energy technology perspectives 2010 - scenarios \& strategies to 2050 (executive summary). Paris, OECD/IEA.

IEA (2011). Technology roadmap - smart grids. D. Elzinga and S. Heinen. Paris, OECD-International Energy Agency.

Ilmarinen, J. (2006). Towards a longer work life: aging and the quality of work life in the European Union. . Helsinki, National Institute for Occupational Health. IPCC-WGII (2014). Summary for Policymakers. Climate Change 2014: Impacts, adaptation and vulnerability. Contribution of Working Group II to the Fifth Assessment Report of the Intergovernmental Panel on Climate Change. Cambridge, Cambridge University Press.

ISO26000 (2010). ISO:26000:2010 Guidance on social responsibility. Geneva, International Standards Organisation.

Jamshidi, M., Ed. (2009b). Systems of systems engineering - principles and applications. Boca Raton, CRC Press.

Johnstone, S., A. Dainty and A. Wilkinson (2008). Delivering 'product-service': key challenges for Human Resource Management. Loughborough, UK, Loughborough University.

Kagermann, H., W. Wahlster and J. Helbig (2013). Recommendations forimplementing the strategic initiative INDUSTRIE 4.0, acatech: National Academy of Science and Technology.

Lavery, G., N. Penell, S. Brown and S. Evans (2013). The next manufacturing revolution: non-labour resource productivity and its potential for UK manufacturing. Cambridge, UK, Institute for Manufacturing, Cambridge University: 164.

Lavery/Penell (2014). The new industrial model. London, Lavery/Pennell. Lee, B., F. Preston, J. Kooroshy, R. Bailey and G. Lahn (2012). Resource futures. London, Royal Institue of International Affairs, Chatham House.

Levermann, A. (2014). "Climate economics: Make supply chains climate-smart." http://www.nature.com/news/climate-economics-make-supply-chains-climatesmart-1.14636

\section{http://www.zeean.net.}

Leveson, N. G. (2004). "A new accident model for engineering safer systems." Safety Science 42(4): 237-270.

Maier, M. W. (1998). "Architecting principles for systems-of-systems." Systems Engineering 1(4): 267-284.

Mantovani, G. (1996). New communication environments. Basingstoke, U.K., Taylor \& Francis.

McMichael, A. J. and K. B. G. Dear (2010). "Climate change: Heat, health, and longer horizons." Proceedings of the National Academy of Science 107(21): 9483-9484.

Merkle, D., M. Middendorf and A. Scheidler (2008). Organic computing and swarm intelligence. Swarm Intelligence. C. Blum and D. Merkle. Heidelberg, Springer. 
MoE(Japan) (2008). Fundamental plan for establishing a Sound Material-cycle Society. Tokyo, Ministry of the Environment.

Naumann, E. (2006). The Multifibre Agreement - WTO agreement on textiles and clothing, Trade Law Centre for Southern Africa,

P.0. Box 224, Stellenbosch, South Africa, South Africa.

Phone: +27 (0)21 883 2208, 883 8292, URL: http://www.tralac.org.

NCOIC (2011). NCOIC Interoperability Framework 2.1. Washington, DC, Network Centric Operations Industry Consortium.

O'Neill, D. H. (2009). Ergonomics issues in transport. Ergonomics in developing regions. P. A. Scott. Boca Raton, Fla, CRC press: 153-169.

Ortiz, A. M., D. Hussein, S. Park, S. N. Han and N. Crespi (2014). "The cluster between Internet of Things and Social Networks: review and research challenges." IEEE Internet of Things Journal 1(3): 206-215.

Parasuraman, R., T. B. Sheridan and C. D. Wickens (2000). "A model for types and levels of human interaction with automation." IEEE Transactions on Systems, Man \& Cybernetics 30(3): 286-297.

Perrow, C. (1999). Normal accidents - living with high-risk technologies.

Princeton, NJ, princeton University Press.

Pétrissans, A., S. Krawczyk, L. Veronesi, G. Cattaneo, N. Feeney and C. Meunier (2012). Design of future Embedded Systems toward system of systems - trends and challenges.

Prior, T., D. Giurco, G. Mudd, L. Mason and J. Behrisch (2012). "Resource depletion, peak minerals and the implications for sustainable resource management." Global Environmental Change 22(3): 577-587.

Rees, P., N. v. d. Gaag, J. d. Beer and F. Heins (2012). "European regional populations: current trends, future pathways, and policy options." European Journal of Population 28: 385-416.

Roberts, K. H. and R. Bea (2001). "When Systems Fail." Organizational Dynamics 29(3): 179-191.

Rochlin, G., T. D. LaPorte and K. H. Roberts (1987). "The self-designing highreliability organisation: aircraft carrier flight operations at sea." Naval War College Review 40: 76-90.

Schätz, B. (2014). The role of models in engineering of cyber-physical systems challenges and possibilities. CPS20: CPS 20 years from now - visions and challenges. Berlin.

Siderius, P. J. S. and H. Nakagami (2007). Top Runner in Europe? Inspiration from Japan for EU ecodesign implementing measures. Summer Study Series. Stokholm, European Council for an Energy Efficient Economy: 1119-1126.

Siemieniuch, C. E. and M. A. Sinclair (2008). "Using corporate governance to enhance 'Long-Term Situation Awareness' and assist in the avoidance of organisation-induced disasters." Applied Ergonomics: 229-240.

Siemieniuch, C. E. and M. A. Sinclair (2012). Socio-technical considerations for enterprise system interfaces in systems of systems. 7th International

Conference on System of Systems Engineering - IEEE SoSE 2012. R. Sacile. Genoa, Italy, IEEE.

Siemieniuch, C. E. and M. A. Sinclair (2014). "Extending systems ergonomics thinking to accommodate the socio-technical issues of Systems of Systems." Applied Ergonomics 45(1): 85-98. 
Siemieniuch, C. E. and M. A. Sinclair (2015). Methods in systems ergonomics. Evaluation of Human work. J. Wilson and S. Sharples.

Sulston, J. (2012). People and the planet. London, The Royal Society.

Takewaki, I., M. Nakamura and S. Yoshitomi (2011). System identification for struhealth monitoring. Boston, WIT Press.

Tannenbaum, S. I., E. Salas and J. A. Cannon-Bowers (1996). Promoting team effectiveness. Handbook of work group psychology. M. A. West. Chichester, UKJ. Wiley \& Sons: 503-529.

Tojo, N. and I. Tanaka (2005). The Top-runner program in Japan. Stockholm, Naturvårdsverket (Swedish Environment Protection Agency).

Turner, B. A. and N. F. Pidgeon (1997). Man-made disasters. London, Butterworth-Heinemann.

UN-DESA (2004). World population to 2300.

UN-FAO (2009). How to feed the world in 2050.

UNEP (2013). The Emissions Gap Report 2013. Nairobi, Kenya, United Nations Environment Programme (UNEP).

UNHRC (2011). Guiding prnciples on business and human rights. New York, UN Human Rights Council.

Vlacheas, P., R. Giaffreda, V. Stavroulaki, D. Kelaidonis, V. Foteinos, G. Poulios, P. Demestichas, A. Somov, A. R. Biswas and K. Moessner (2013). "Enabling Smart Cities through a cognitive management framework for the Internet of Things." IEEE Communications Magazine: 102-111.

WEF (2013). Global risks 2013 - testing economic and environmental resilience. Davos, Switzerland, World Econmic Forum.

Weick, K. E. and K. H. Roberts (1993). "Collective mind in organisations: heedful inter-relating on the flight decks." Administrative Sciences Quarterly 38: 357381.

WETO-H2 (2006). World energy technology outlook - 2050. Brussels, Directorate Energy, European Commission.

Whitworth, B. and A. d. Moor (2003). "Legitimate by design: towards trusted socio-technical systems." Behaviour \& Information Technology 22(1): 31-51. World-Bank (2012). Turn down the heat: why a $4^{\circ} \mathrm{C}$ warmer world must be avoided. Washington, DC, World Bank.

World-Bank (2012). World Bank sees progress against extreme poverty, but flags vulnerabilities. Washington, DC, The World Bank.

Zink, K. (2013). "Designing sustainable work systems: The need for a systems approach." Applied Ergonomics 45: 126-132.

Zivin, J. G. and M. J. Niedell (2010). Temperature and the allocation of time: the implications for climate change. Cambridge, MA, National Bureau of Economic Research. 